Jahrbuch für Geschichte Lateinamerikas Anuario de Historia de América Latina

54 | 2017 | 211-257

Sarah Albiez-Wieck

Universität zu Köln

Tributgesetzgebung und ihre Umsetzung in den Vizekönigreichen Peru und Neuspanien im Vergleich
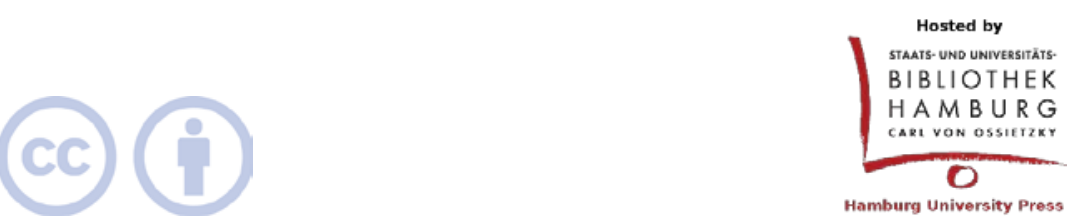

Except where otherwise noted, this article is licensed under a Creative Commons Attribution 4.0 International license (CC BY 4.0)

https://doi.org/10.15460/jbla.54.25 


\title{
Tributgesetzgebung und ihre Umsetzung in den Vizekönigreichen Peru und Neuspanien im Vergleich
}

\author{
Sarah Albiez-Wieck
}

\begin{abstract}
Indigenous and afrodescendant tribute payments constituted the central manifestation of the colonial relationship between the Americas and the Spanish crown. This article outlines the development of colonial tributary legislation and its implementation in the viceroyalties of New Spain and Peru from the $16^{\text {th }}$ to the $19^{\text {th }}$ century. It focuses on tribute categories as decisive factors for the formation of the colonial society. The comparative approach reveals that the major differences between New Spain and Peru lay first in the tribute categories for "migrants" and second in the varying degree of implementation of tribute obligations among the afrodescendant population.
\end{abstract}

Keywords: Tariffs; Categories; Colonial Era; Migration; Bourbon Reforms; sociedad de castas.

Resumen. - El tributo que pagaba la población indígena y afrodescendiente en Hispanoamérica constituyó de manera central la relación colonial con la corona española. El presente artículo expone el desarrollo de la legislación tributaria y su implementación en los virreinatos de Nueva España y Perú durante los siglos XVI a $\mathrm{XIX}$. Se enfoca en las categorías tributarias como aspectos significativos en la constitución del orden social colonial. El análsis comparativo evidencia que las diferencias principales entre Nueva España y Perú consistían en primer lugar en las categorías tributarias "migrantes" y en segundo lugar en el grado de implementación de la obligación tributaria para la población afrodescendiente.

Palabras clave: impuestos; categorías; era colonial; migración; reformas borbonicas; sociedad de castas. 


\section{Einleitung ${ }^{1}$}

„Porque es cosa justa, y razonable, que los Indios, que se pacificaren, y reduxeren á nuestra obediencia, y vassallaje, nos sirvan, y dén tributo en reconocimiento del señorio, y servicio, que como nuestros subditos, y vassallos deven, pues ellos tambien entre si tenian costumbre de tributar á sus Tecles, y Principales. Mandamos, que se les persuada á que por esta razon nos acudan con algun tributo en moderada cantidad.“2

Diese Begründung für die Einforderung von Tributzahlungen von der indigenen Bevölkerung Hispanoamerikas stammt aus der Recopilación de Leyes de Indias. In ähnlicher Form tauchte sie in vielen kolonialzeitlichen Quellen auf, die sich in der einen oder anderen Form mit Tributzahlungen beschäftigten. ${ }^{3}$ Neben der Christianisierung und religiösen Unterweisung war die Leistung von Tributzahlungen und Arbeitsdiensten das Element, welches die indigene Bevölkerung am intensivsten und dauerhaftesten mit der spanischen Krone verband und damit das spürbarste Element der kolonialen Beziehung und Gegenstand zahlreicher Aushandlungsprozesse und Konflikte. Der Tribut war somit ein zentrales Merkmal der spanischen Herrschaft in den Amerikas. In den Worten Serulnikovs war er ein „Herzstück des spanischen Kolonialismus“ ${ }^{4}$ und symbolisierte den „kolonialen Pakt“ oder den „Tributpakt“. Dieser besagte, dass die Indigenen Schutz durch den spanischen König erhielten sowie die Erlaubnis zur Landbearbeitung und im Gegenzug hierfür Tribut zahlten. ${ }^{5}$ Allerdings lässt dieses Verständnis

1 Die dem Artikel zugrundeliegende Forschung wurde von der Deutschen Forschungsgemeinschaft sowie der Universität zu Köln im Rahmen der Exzellenzinitiative (UoC Forum Ethnicity as a Political Ressource) gefördert. Ich danke Raquel Gil Montero, Silke Hensel, Katja Reuter sowie den anonymen Gutachter_innen für ihre Kommentare.

2 „De los tributos, y tassas de los indios. Libro 6, Título V”, Recopilación de Leyes de los Reinos de las Indias, Madrid, 1680, http://www.leyes.congreso.gob.pe/ leyes_indias.aspx [17-01-17], Ley I.

${ }^{3}$ In der Real Ordenanza de Intendentes von 1786 wird dies folgendermaßen formuliert: „el Real Tributo que pagan á mi Soberanía en reconocimiento del vasallage y suprema protección que les está concedida”: Real Ordenanza para el Establecimiento é Instruccion de Intendentes de Exército y Provincia en el Reino de la Nueva-España. De Orden de Su Magestad, Madrid, 1786. https://archive.org/stream/realordenanzapar01nvguat\#page/ 164/mode/2up [27-10-16], Art. 13, S. 21-22.

${ }^{4}$ Sergio Serulnikov, „Customs and Rules. Bourbon Rationalizing Projects and Social Conflicts in Northern Potosí during the 1770s”: Colonial Latin American Review, 8: 2 (1999), S. 245-274, S. 260.

${ }^{5}$ Serulnikov, „Customs and Rules“, S. 260; Peter F. Guardino, The Time of Liberty. Popular Political Culture in Oaxaca, 1750-1850, Durham, NC, London: Duke University Press, 2005, S. 25-26, 82; Núria Sala i Vila, Y se armó el tole tole. Tributo indígena y

Jahrbuch für Geschichte Lateinamerikas | Anuario de Historia de América Latina 
des kolonialen Paktes außer Acht, dass nicht alle Indigenen Land besaßen, und dass es auch Gemeinden gab, die sich weigerten Tribut zu zahlen; womit die Allgemeingültigkeit des Paktes in Frage gestellt wird. ${ }^{6}$ Nicht nur die indigene, auch die freie afrikanischstämmige Bevölkerung musste Tributzahlungen leisten - zumindest theoretisch. Für sie funktionierte das Konzept des kolonialen Pakts allerdings nur sehr bedingt.

Gemessen an der Bedeutsamkeit des Themas, die sich auch in der Fülle an Archivmaterial ausdrückt, haben der Tribut und die damit zusammenhängende Gesetzgebung vor allem in jüngerer Zeit vergleichsweise wenig Aufmerksamkeit erfahren. Zwar gab es bereits zum Ende der Kolonialzeit erste Überblicksdarstellungen, ${ }^{7}$ und jedes Handbuch erwähnt das Thema zumindest kurz, wenn es um die indigene Bevölkerung geht, ${ }^{8}$ doch die meisten Überblicksdarstellungen sind schon Jahrzehnte alt - liefern jedoch nichtsdestotrotz wertvolle Analysen für bestimmte Regionen. ${ }^{9}$ Es gibt zwar einige neuere, teils auch sehr gute

movimientos sociales en el Virreinato del Perú. 1790-1814, Ayacucho: Instituto de Estudios Regionales José María Arguedas, 1996, S. 20 spricht von einem „pacto de vasallaje“, laut dem die Indigenen den Tribut im Gegenzug für die eingeräumten Landnutzungsrechte zahlten. Carlos Sánchez Silva, Indios, comerciantes y burocracia en la Oaxaca poscolonial, 1786 - 1860, Oaxaca: Inst. Oaxaqueño de las Culturas, 1998, S. 121 ist hingegen der Ansicht, dass der König die Landrechte der Indigenen tatsächlich anerkannte. Dieser Sicht schließe ich mich an, da in den von mir eingesehenen Quellen stets vom Landbesitz und nicht nur von einem Nutzungsrecht die Rede ist.

${ }^{6}$ Raquel Gil Montero, La construcción de Argentina y Bolivia en los Andes Meridionales. Población, tierras y ambiente en el siglo XIX, Buenos Aires: Prometeo Libros, 2008, S. 206. Siehe auch: Cecilia Méndez, „República sin indios. La comunidad imaginada del Perú”: Henrique Urbano (Hg.), Tradición y modernidad en los Andes, Cusco: 1992, S. 15-41.

${ }^{7}$ Fabián de Fonseca / Carlos de Urrutia, Historia general de Real Hacienda, México, 1845. Online: http://cdigital.dgb.uanl.mx/la/1080018423_C/1080018423_T1/ 1080018423_T1.html [14-03-17], S. 411-551. Dieses Werk wurde bereits 1791 auf Anweisung des Vizekönigs Conde de Revillagigedo erstellt, jedoch erstmals 1845 publiziert.

${ }^{8}$ Z.B. Silke Hensel / Barbara Potthast (Hg.), Das Lateinamerika-Lexikon, Wuppertal: Peter Hammer Verlag, 2013; Leslie Bethell (Hg.), Historia de America Latina. América Latina colonial. Poblacion, sociedad y cultura, Barcelona: Critica, 2000, Bd. 4.; Walther L. Bernecker (Hg.), Handbuch der Geschichte Lateinamerikas, Stuttgart: Klett-Cotta, 1996.

${ }^{9}$ Z.B. José Miranda, El tributo indígena en la Nueva España durante el siglo XVI, México: El Colegio de México, 1952; Charles Gibson, Los aztecas bajo el dominio español (1519-1810), México, D.F.: Siglo Veintiuno Ed, 1964, Bd. 15, Kap. 8; Nicolás Sánchez-Albornoz, Indios y tributos en el Alto Perú, Lima: Instituto de Estudios Peruanos, 1978, Bd. 6.; Pilar Remy S., „Tasas tributarias pre-toledanas de la provincia de Cajamarca. (Pre-Toledo Lists of Tribute Requirements of the Province of Cajamarca)“: Historia y Cultura, 16 (1988), S. 67-82. Das Werk von Rojas ist recht oberflächlich: José 
Studien, doch mit Ausnahme eines kürzlich erschienen Artikels von Pollack, ${ }^{10}$ haben sowohl die neueren als auch die älteren Werke oft einen begrenzten regionalen und meist auch zeitlichen Fokus. ${ }^{11}$ Besondere Beachtung finden in der Regel das 16. sowie das 18. Jahrhundert im Kontext der bourbonischen Reformen; das 17. Jahrhundert ist oft wenig erforscht. ${ }^{12}$ Es gibt zwar umfassende quantitative Studien zur Höhe der Tributeinnahmen als Teil des Steuersystems insgesamt, diese beschäftigen sich aber nur am Rande mit Gesetzgebung und Kategorien. ${ }^{13}$ Aufgrund der Bedeutung des Tributs findet dieser, ebenso

Luis de Rojas, A cada uno lo suyo. El tributo indígena en la Nueva España en el siglo XVI, Zamora: El Colegio de Michoacán, 1993.

${ }_{10}$ Pollack arbeitet auch hauptsächlich zu Neuspanien bzw. zur Audiencia de Guatemala, hat aber einen vergleichenden Artikel geschrieben, der das 16.-19. Jahrhundert umfasst, jedoch das 17. Jahrhundert kaum behandelt: Aaron Pollack, „Hacia una historia social del tributo de indios y castas en Hispanoamérica. Notas en torno a su creación, desarrollo y abolición”: Historia Mexicana, 66: 1 (2016), S. 65-156. Außerdem zu nennen ist ein älterer Artikel von Díaz Rementería, der die bourbonischen Reformen zum Bereich Tribute in Peru, Neuspanien und Río de la Plata vergleicht und gegenseitige Einflüsse nachzeichnet: Carlos Díaz Rementería, 2El régimen jurídico del ramo de tributos en Nueva España y las reformas peruanas de Carlos III”: Historia Mexicana, 66: 4 (1979), S. 401-438.

${ }^{11}$ Für Neuspanien, insbesondere für die zweite Hälfte des 18. Jahrhunderts hat Terán mehrere Studien vorgelegt, und auch eine sehr empfehlenswerte Software erstellt, die zahlreiche Transkriptionen von wichtigen Quellen enthält: Martha Terán, Tributos tardíos de la Nueva España. Programa interactivo, México, D.F.: 2016; eadem, „Geografía de los partidos tributarios de la Nueva España. Los subdelegados como recaudadores de los tributos, 1805-1810”: Rafael Diego-Fernández Sotelo / María Pilar Gutiérrez Lorenzo / Arrioja Díaz Viruell, Luis Alberto (Hg.), De reinos y subdelegaciones. Nuevos escenarios para un nuevo orden en la América borbónica, Zamora, Michoacán: El Colegio de Michoacán; Universidad de Guadalajara; El Colegio Mexiquense, 2014, S. 73-116. Für den Zusammenhang mit den bourbonischen Reformen gibt es mehrere Arbeiten, siehe z.B. Netzahualcóyotl Luis Gutiérrez Núñez, „La Real Hacienda y la Ordenanza de Intendentes de 1786. Ensayo sobre su estructura y funcionamiento a partir del caso de Valladolid de Michoacán: 1786-1820”: Jorge Silva Riquer (Hg.), Historia de la hacienda pública en Michoacán, 1786-1951. Una historia larga, Morelia, Michoacán, México: Universidad Michoacana de San Nicolas de Hidalgo, Facultad de Historia, PIFI, 2014, S. 19-84. Für Peru, inklusive der Phase der Unabhängigkeit, siehe Carlos Contreras, „El impuesto de la contribución personal en el Perú del siglo XIX”: Histórica, 29: 2 (2005), S. 67-106.

${ }^{12}$ In Neuspanien ist dies möglicherweise teilweise dadurch begründet, dass Ende des 17. Jahrhunderts ein Feuer im vizeköniglichen Palast einen großen Teil der Manuskripte der Contaduría de Tributos zerstörte: Cayetano Reyes García (Hg.), Catálogo del ramo tributos, México, D.F: AGN, 1981, S. V-VI. Interessanterweise haben im Vizekönigreich Peru viele der Studien zu indigener Migration, die sich oft mit Aspekten von Tribut- und Arbeitsdiensten befassen, einen Fokus auf dem 17. Jahrhundert.

${ }^{13}$ Herbert S. Klein, The American Finances of the Spanish Empire. Royal Income and Expenditures in Colonial Mexico, Peru, and Bolivia, 1680 - 1809, Albuquerque, NM: Univ. of New Mexico Press, 1998; Herbert S. Klein / Laura Elena Pulido Varela, 
wie die zugehörigen Gesetze und Kategorien, allerdings in einer Fülle von Arbeiten Erwähnung. Bei einigen davon nimmt er einen besonders hohen Stellenwert in der Verschränkung mit anderen Thematiken ein. Dies gilt etwa für Studien, die sich mit dem Themenkomplex Migration, insbesondere im Vizekönigreich Peru, beschäftigen ${ }^{14}$ und solche Arbeiten, die Quellen wie die Visitationen für sozialgeschichtliche und demografische Fragestellungen verwenden. ${ }^{15}$ Einzelne Arbeiten beschäftigen sich auch mit Verbindungslinien zwischen Tribut und Zugehörigkeit bzw. Identität, nicht nur bei Indigenen. ${ }^{16}$ Insgesamt

„Historia fiscal colonial. Resultados y perspectivas”: Historia Mexicana (México e Hispanoamérica. Una reflexión historiográfica en el Quinto Centenario I), 42: 2 (1992), S. 261-307; John Jay TePaske / Herbert S. Klein / Kendall W. Brown, The Royal Treasuries of the Spanish Empire in America, Durham, N. C.: Duke University Press, 1982 (3 Bde.).

${ }^{14}$ Beispielsweise für Peru: Laura Escobari de Querejazu, Caciques, yanaconas y extravagantes. La sociedad colonial en Charcas, La Paz, Bolivia: IFEA, 2005, Bd. 208, S. XVI-XVIII; Raquel Gil Montero, „Migración y tributación en los Andes. Chichas y Lípez a fines del siglo XVII”: Anuario de Estudios Americanos, 70: 1 (2013), S. 39-65; Raquel Gil Montero / Lía Guillermina Oliveto / Fernando Longhi, „Mano de obra y fiscalidad a fin del siglo XVII. Dispersión y variabilidad de la categoría yanacona en el sur andino": Boletín del Instituto de Historia Argentina y Americana "Dr. Emilio Ravignani”, Tercera serie, 43 (2015), S. 59-93; Karen Vieira Powers, Andean Journeys. Migration, Ethnogenesis, and the State in Colonial Quito, Albuquerque: University of New Mexico Press, 1995; Ann M. Wightman, Indigenous Migration and Social Change. The Forasteros of Cuzco, 1570-1720, Durham: Duke University Press, 1990.

${ }^{15}$ Z.B. Noble David Cook / Málaga Medina, Tasa de la visita general de Francisco de Toledo, Lima: Universidad Nacional Mayor de San Marcos, 1975; R. Alan Covey / Christina M. Elson, „Ethnicity, Demography, and Estate Management in SixteenthCentury Yucay”: Ethnohistory, 54: 2 (2007), S. 303-335; Maria de Diez-Canseco, „Visitas de indios en el siglo XVI”: Cahiers du Monde Hispanique et Luso-brésilien, 7, Actes Du Colleque Sur Littérature et Histoire du Perou (1966), S. 85-92; Karoline Noack, „Die Visitation des Greogrio González de Cuenca (1566/67) in der Nordregion des Vizekönigreiches Peru. Gesellschaftliche Relevanz von Rechtsordnung und Rechtsanwendung”: European Review of Latin American and Caribbean Studies, 61 (1996), S. 133-135.

${ }^{16}$ Granados beschäftigt sich mit Tributbelegen als Identifizierungsmöglichkeit von Indigenen in Mexiko-Stadt: Luis Fernando Granados, „Pasaportes neoclásicos. 'Identidad' y cobro de tributo indígena en la ciudad de México borbónica”: Felipe Castro Gutiérrez (Hg.), Los indios y las ciudades de Nueva España, México: Instituto de Investigaciones Históricas, UNAM, 2010, S. 371-396; Grewe mit Ethnizität und Staatsbürgerschaft sowohl bei Indigenen als auch bei der afrikanischstämmigen Bevölkerung in Neuspanien: David Grewe, Ethnizität, Staatsbürgerschaft und Zugehörigkeit im Zeitalter der Revolution, 2016, Bd. 47. Für Peru bezüglich Indigene, siehe Carmen B. Loza, „¿Estatuto fiscal contra identidad étnica? Criterios de diferenciación social en el sur del Perú (1569-1579)”: Revista Andina, 15: 2 (1997), S. 378-419; für afrodescendientes Ronald Mansilla Escobedo, „El tributo de los zambaigos, negros y mulatos libres en el virreinato peruano”: Revista de Indias, 41: 1 (1981), S. 4354; Christine Hünefeldt, „Esclavitud, percepciones raciales y lo político. La población 
werden die Regelungen zur Tributfestsetzung und Eintreibung nur selten erläutert und auf regionale Unterschiede wird kaum eingegangen.

Dieser Artikel hat sich daher zum Ziel gesetzt, sowohl die rechtlichen Rahmenbedingungen, als auch deren Umsetzung zum Themenbereich Tribut, in ihrer Entwicklung während der gesamten Kolonialzeit nachzuzeichnen. Auch dieser Artikel kann nicht auf alle Regionen und Besonderheiten eingehen. Der Fokus wird auf einem Vergleich der beiden Vizekönigreiche Neuspanien und Peru liegen, die als die beiden frühesten, wichtigsten und größten Vizekönigreiche einen bedeutenden Teil Hispanoamerikas abdecken. Die hier vorgestellte Gesetzgebung galt oft für ganz Hispanoamerika. Die geordnete und kontextualisierte Darstellung dieser Tributgesetzgebung über die gesamte Kolonialzeit hinweg stellt einen wesentlichen Beitrag dieses Artikels dar und geht damit über viele andere Werke mit begrenzterem zeitlichen oder regionalen Fokus hinaus. Im Bereich der Umsetzung sind die Ambitionen des Beitrags regional begrenzter, da mein eigener Forschungsfokus auf den Regionen Cajamarca im Norden Perus, in der Audiencia de Lima, und auf Michoacán in Neuspanien liegen. Inwiefern die dortige Praxis auf andere Regionen übertragbar ist, lässt sich nicht immer beantworten. Ich werde punktuell auf diese Frage eingehen. Allgemein ist davon auszugehen, dass die dortigen Praktiken kaum repräsentativ für periphere Regionen wie etwa Yucatán in Neuspanien oder Paraguay in Peru waren, ${ }^{17}$ jedoch zumindest in groben Zügen mit dem Gebiet des früheren Inka- und Aztekenreiches übereinstimmten. Dies waren auch die Gebiete, die den Großteil der Tributeinnahmen lieferten und die in der Sekundärliteratur häufig erwähnt werden. ${ }^{18}$

Ein weiterer wichtiger Beitrag des Artikels ist die systematische Herausarbeitung der verschiedenen Tributkategorien und der diesbezügliche Vergleich der beiden Vizekönigreiche. Dabei wird offengelegt, dass die zentralen Tributkategorien - Indigene und „freie Schwarze“ bzw. „Mulatten“ ${ }^{19}$ - ähnlich definiert waren. Die

negra en la era independentista en Hispanoamérica”: Heraclio Bonilla (Hg.), Indios, negros y mestizos en la independencia, Bogotá: Editorial Planeta Colombiana, 2010, S. 270-289.

${ }^{17}$ In Paraguay unterschied sich etwa die Bedeutung der Kategorien yanacona, originario und mitayo von der in anderen Teilen des Vizekönigreiches: Ignacio Telesca, Tras los expulsos. Cambios demográficos y territoriales en el Paraguay después de la expulsión de los jesuitas, Asunción, Paraguay: Universidad Católica "Nuestra Señora de la Asunción”, 2009, S. 27-78.

${ }^{18}$ Klein, The American Finances, S. 20.

${ }^{19}$ Da der Mann als Tributzahler registriert wurde und auch die Empfänger des Tributs bzw. die Verwaltungsbeamten männlich waren, wird im Text größtenteils die männliche 
Durchsetzung der Tributpflicht für die freie afrikanischstämmige Bevölkerung hatte jedoch in Peru eine deutlich geringere Reichweite. Außerdem divergierte die weitere Auffächerung der Kategorien teilweise stark. Dies galt insbesondere für Kategorien mit Bezug zu Migration die sich nicht nur zwischen, sondern auch innerhalb der einzelnen Regionen in den jeweiligen Vizekönigreichen unterschieden. Dies zeigt einmal mehr die Notwendigkeit der Untersuchung konkreter regionaler Fallbeispiele.

Die wichtigsten fiskalischen Kategorien, d.h. Spanier, Mestize, Mulatte und Indigener, korrelierten mit den Kategorien des sogenannten casta-Systems. In der Forschung werden die verschiedenen castas zumeist als ethnische oder rassifizierte ${ }^{20}$ Kategorien bezeichnet, wobei die Mehrheit der Autor_innen der Ansicht ist, dass hierbei religiöse,

Sprachform genutzt. Wenn zu vermuten ist, dass besprochene Gruppe bzw. Kategorie auch Frauen enthielt, wird dies entsprechend sprachlich deutlich gemacht. Da die versklavte Bevölkerung naturgemäß keinen Tribut zu zahlen hatte, werde ich im Weiteren nicht auf diese eingehen und werde, wenn ich von afrikanischstämmige Bevölkerung spreche, stets nur jene Anteile meinen, die nicht (mehr) versklavt waren.

20 Die Positionen in der internationalen Forschung reichen bezüglich der Unterscheidung zwischen den Termini Rasse und Ethnizität von einer völligen Ablehnung des Konzepts Rasse, über die Anerkennung der Existenz von Rassismus und einer Gleichstellung mit oder Unterordnung unter das Konzept Ethnizität, bis hin zur klaren Trennung der Beiden. Vgl. Floya Anthias, „Rethinking Social Divisions. Some Notes Towards a Theoretical Framework”: The Sociological Review, 46: 3 (1998), S. 505-535; Marion Müller / Darius Zifonun, „Wissenssoziologische Perspektiven auf ethnische Differenzierung und Migration. Eine Einführung”: Marion Müller / Darius Zifonun (Hg.), Ethnowissen. Soziologische Beiträge zu ethnischer Differenzierung und Migration, Wiesbaden: VS Verlag für Sozialwissenschaften (GWV), 2010, S. 9-32; Claudio Lomnitz, „Nationalism as a Practical System. Benedict Anderson's Theory of Nationalism from the Vantage Point of Spanish America”: Miguel Angel Centeno (Hg.), The Other Mirror. Grand Theory Through the Lens of Latin America, Princeton: Princeton University Press, 2001, S. 328-359; Peter Wade, „Race in Latin America”: Deborah Poole (Hg.), A Companion to Latin American Anthropology, Malden, MA: Blackwell Pub, 2008, S. 177-192. Mara Loveman, „Is 'Race“ essential?”: American Sociological Review, 64: 6 (1999), S. 891-989 hat aufgezeigt, dass die meisten Definitionen von Rasse tautologisch sind und dass ein grundsätzlicher analytischer Unterschied zwischen „Race“ und „Ethnicity“ bislang nicht überzeugend nachgewiesen werden konnte. Auch zahlreiche andere Autoren, wie etwa Wade, „Race in Latin America”, S. 184 haben argumentiert, dass beispielsweise die Unterscheidung zwischen Indigenen und Mestizen zwar oft als ethnisch angesehen wird, weil sie „kulturelle“ Unterscheidungen wie Sprache, Kleidung und Verhalten zu umfassen scheinen, statt „rassische“ Unterscheidungen wie Aussehen und Abstammung, aber dass diese konzeptuelle Trennung nicht angebracht ist. Sowohl ethnische als auch „rassische“ bzw. rassistische Kategorien sind gleichermaßen sozial konstruiert, auch wenn sie physische Kriterien verwenden. Um den Anschein zu vermeiden, dass es tatsächlich menschliche „Rassen“ gebe, werde ich nur über rassifizierte Kategorien sprechen.

Jahrbuch für Geschichte Lateinamerikas | Anuario de Historia de América Latina 
sozioökonomische und kulturelle Kriterien zusammenspielten. Oft werden auch fiskalische Kriterien als wichtiges Element der Herausbildung der sozialen Kategorien im casta-System genannt. Zahlreiche Historiker_innen haben die Frage kontrovers diskutiert, inwiefern diese klar differenzierten castas bedeutsam für das alltägliche Leben in der kolonialzeitlichen Gesellschaft waren, und welchen Stellenwert die verschiedenen Kriterien der Zuordnung einnahmen. Es wird im Allgemeinen davon ausgegangen, dass die castaKategorisierungen bis $\mathrm{zu}$ einem gewissen Grad flexibel und kontextabhängig waren, und dass ein rassifizierte Kriterium höchstens eines unter anderen darstellten. ${ }^{21}$ Bei der Diskussion muss stets berücksichtigt werden, dass es neben dem casta-System noch weitere Modelle zur Ordnung der kolonialen Gesellschaft gab. Diese umfassten das Modell der zwei Republiken ${ }^{22}$ und das Modell gente decente -

\footnotetext{
${ }^{21}$ Einige gute, und häufig zitierte Studien bzw. Sammelbände zur Thematik sind: R. Douglas Cope, The Limits of Racial Domination. Plebeian Society in Colonial Mexico City; 1660 - 1720, Madison, Wisconsin: University of Wisconsin Press, 1994; Rachel Sarah O'Toole / Sherwin K. Bryant / Ben Vinson (Hg.), Africans to Spanish America. Expanding the Diaspora, Urbana: University of Illinois Press, 2012; Verena Stolcke, „Los mestizos no nacen sino que se hacen”: Verena Stolcke / A. Coello de la Rosa (Hg.), Identidades ambivalentes en América Latina (siglos XVI-XXI), Barcelona: Edicions Bellaterra, 2008, S. 14-51; Nikolaus Böttcher / Bernd Hausberger / Max-Sebastián Hering Torres (Hg.), El peso de la sangre. Limpios, mestizos y nobles en el mundo hispánico, México: El Colegio de México, 2011. Noack stellt als einige der wenigen die Existenz ethnischer Kriterien für ihr Fallbeispiel Trujillo im 16. und 17. Jahrhundert grundsätzlicher in Frage: Karoline Noack, „La construcción de diferencia en la zona de contacto. Interrogantes al respecto de la etnicidad”: Sarah Albiez / Nelly Castro / Lara Jüssen / Eva Youkhana (Hg.), Ethnicity, Citizenship and Belonging. Practices, Theory and Spatial Dimensions, Frankfurt a.M., Madrid: Vervuert; Iberoamericana, 2011, S. 3563.

${ }^{22}$ In der república de indios sollten Indigene getrennt von und geschützt vor in der república de españoles lebenden Spaniern wohnen; außerdem hatten sie einen anderen Rechtsstatus. Die afrikanischstämmige Bevölkerung wurde der república de españoles zugeordnet, die Zuordnung von Mestizen variierte. Es existierte diesbezüglich eine umfangreiche Gesetzgebung, die versuchte, die Gruppen nicht nur rechtlich, sondern auch räumlich zu trennen, was jedoch in der Praxis meist nur ansatzweise funktionierte, trotz zahlreicher Anweisungen zur Ausweisung von Mulatten und Spaniern aus den pueblos de indios. Siehe z.B. „De las reducciones y pueblos indios. Libro 5, Título III”, Recopilación de Leyes de los Reinos de las Indias, Madrid, 1680, Ley 21: Que en los Pueblos de Indios no vivan Españoles, Negros, Mestizos, y Mulatos; Sobre tierras de españoles en pueblos de indios, 2 fs, 1740, AHCP, Caja 132, Leg. 3, Exp. 3; Ordenanza del corregidor de Cajamarca, D. Pedro Díaz de Urbina, disponiendo que los españoles, mestizos y mulatos que no poseen haciendas, trabajo, ni sean casados salgan de la villa de Cajamarca, 15 fs, 11.04.1636-05.04.1664, ARC, Corregimiento, Causas ordinarias, Leg 24.
}

Jahrbuch für Geschichte Lateinamerikas | Anuario de Historia de América Latina 
plebe. ${ }^{23}$ Das casta-System wurde erst in der zweiten Hälfte der Kolonialzeit und mit unterschiedlichen regionalen Schwerpunkten bedeutsam. Die systematische Erläuterung der verschiedenen Tributkategorien in diesem Artikel kann somit auch einen kleinen Beitrag zur größeren Debatte über kolonialzeitliche gesellschaftliche Modelle leisten.

Ein wichtiger Faktor, der das Funktionieren der gesellschaftlichen Modelle in Frage stellte, war Migration. So hatte die Migration von Europäern in die Amerikas erst zu diesen Modellen sowie zur Entstehung der Kategorie indio und später Mestize geführt, zum anderen mündete die Zwangsmigration afrikanischer Bevölkerung in der Formierung weiterer Kategorien und castas. Asiatische Migrant_innen, die auch teilweise unfreiwillig migrierten, fanden in den Modellen gar keinen Platz. ${ }^{24}$ Darüber hinaus führten die verschiedenen Formen interner Migration von Indigenen zur Entstehung weiterer Tributkategorien. Interessanterweise waren es gerade diese Kategorien, die sich im Vergleich der Vizekönigreiche unterschieden, weshalb ihnen ein besonderer Platz eingeräumt werden soll.

Der Artikel ist chronologisch aufgebaut und durch die verschiedenen Tributkategorien strukturiert; die regionalen Besonderheiten in Peru und Neuspanien werden im Wechsel vorgestellt. Vorangestellt wird ein Abschnitt über Belastungen, die die tributpflichtige Bevölkerung zusätzlich zum Tribut zu leisten hatte. Der Hauptteil zum Thema Tribut besteht aus zwei Teilen. Der erste Teil umfasst die Zeit von der Eroberung bis zu den bourbonischen Reformen und stellt die jeweiligen Tributkategorien nebeneinander. Wie sich diese Tributkategorien bzw. ihr Verhältnis untereinander änderte, wird anschließend im Teil zu den bourbonischen Reformen herausgearbeitet. Schließlich wird der lange Weg zur Abschaffung der Tributpflicht kurz nachgezeichnet und abschließend die Hauptlinien der Argumentation kurz zusammengefasst.

\footnotetext{
${ }^{23}$ Cope, The Limits of Racial Domination, S. 22.

${ }^{24}$ Edward Slack, „Sinifying New Spain. Cathay's Influence on Colonial Mexico Via the 'Nao de China'”: Walton Look Lai / Chee-Beng Tan (Hg.), The Chinese in Latin America and the Caribbean, Leiden: Brill, 2010, S. 7-34; Tatiana Seijas, Transpacific Servitude. The Asian Slaves of Mexico, 1580-1700, 2008 (Dissertation).
} 


\section{Weitere Belastungen: Alcabala, Arbeitsdienste und repartimiento de mercancías}

Neben dem Tribut im engeren Sinne, in Form von Sach- und Geldleistungen, hatte die tributpflichtige Bevölkerung noch eine Reihe anderer Pflichten gegenüber der Krone bzw. den Spaniern, denen die Krone die Nutznießung übertragen hatte. In der Praxis waren diese verschiedenen Verpflichtungen eng verknüpft; analytisch ist es jedoch möglich, diese zu trennen, auch um den Rahmen dieses Artikels nicht zu sprengen. ${ }^{25}$ Die wichtigsten Verpflichtungen sollen daher hier kurz genannt werden, um nicht den Eindruck zu erwecken, dass der Tribut die einzige Verpflichtung darstellte. Sie umfassten die Verkaufssteuer, genannt alcabala, Arbeitsdienste, das sogenannte repartimiento de mercancías, sowie Abgaben an die Kirche.

Die genannten Obligationen unterschieden sich stark für die indigene und die afrikanischstämmige Bevölkerung. Letztere musste hauptsächlich die Verkaufssteuer, alcabala, entrichten. Dies war auch eine bedeutsame Belastung für die spanische und mestizische Bevölkerung, die keine Tributzahlungen $\mathrm{zu}$ leisten hatten. ${ }^{26}$ Ausgenommen von der alcabala waren indigene Produkte, sogenannte productos de la tierra. Indigene mussten jedoch die alcabala bezahlen, wenn sie mit spanischen Produkten handelten. ${ }^{27}$ Im Zuge der bourbonischen Reformen initiierten Gálvez in Neuspanien und Areche in Peru eine Ausweitung der alcabala-Pflicht auf Indigene bzw. indigene Produkte. In Neuspanien wurde dies mit Ausnahme einer kurzen

${ }^{25} \mathrm{Zu}$ einer analytischen Trennung von Arbeitsdiensten und Tribut, vgl. Raquel Gil Montero / Paula C. Zagalsky, „Colonial Organization of Mine Labour in Charcas (Present-Day Bolivia) and Its Consequences. Sixteenth to the Seventeenth Centuries": Internationaal Instituut voor Sociale Geschiedenis, 61 (2016), S. 71-92, hier S. 85-86. Die Autorinnen beschreiben das Verhältnis von Tribut und Arbeitsdiensten in der Audiencia de Charcas zwischen 1570 und 1680 folgendermaßen: „We found three different situations: one in which some tributaries had to pay their tributes in money, and they worked to earn this money; another in which they had to work as forced labourers (mitayos) and to pay their tributes as well; and a third in which they sometimes had to work and were not obliged to pay tributes in money, as was the case with the yanaconas.”.

${ }^{26}$ Als Beispiel für die Zahlung der alcabala durch Mestizen, siehe Fabián y Luisa Sánchez, vecinos del pueblo de Chota, hijos naturales de Gregorio Sánchez, cuarterón de español y de María Delgado, mestiza, solicitando se los exhonere del pago de tributos por ser mestizos, 10 fs, 22.08.1770-14.02.1789, ARC, Corregimiento, Causas ordinarias, Tributos, Leg 05.

${ }^{27}$ Margarita Menegus Bornemann, „Alcabala o tributo. Los indios y el fisco (siglos XVI al XIX)”: Luis Jáuregui / Antonio Serrano (Hg.), Las finanzas públicas en los siglos XVIII-XIX, México: UNAM, 1998, S. 110-130, hier S. 116-117.

Jahrbuch für Geschichte Lateinamerikas | Anuario de Historia de América Latina 
Testphase ab 1792 nicht umgesetzt. ${ }^{28}$ In Peru war die Ausweitung der alcabala-Pflicht einer von mehreren Auslösern für die Rebellion von Tupac Amaru in den Jahren 1780-82, die sich auch gegen die Abschaffung der mita und Handelsbeschränkungen richtete. ${ }^{29}$

Für die indigene Bevölkerung waren neben dem Tribut verschiedene Arbeitsdienste die größte Belastung; insbesondere in jenen Gebieten, in denen Minenarbeit zu erbringen war. Sich diesen Arbeitsdiensten zu entziehen war einer der Hauptgründe für die indigene Migration, insbesondere in Peru. Im 16. Jahrhundert standen die Arbeitsdienste in engem Zusammenhang mit der encomienda. Sie bestand darin, dass spanischen Siedlern Tribut und Arbeitskraft einer Gruppe von Indigenen zugeteilt wurde, die eigentlich der Krone zustanden. Es gab große Überlappungen mit dem repartimiento genannten Arbeitsdienst, der schon in der Karibik bestanden hatte. Die den Spaniern dort für „Zwei Leben“ zugeteilten Arbeitskräfte wurden in Anlehnung an vorspanische Praktiken mit dem Taino-Wort naboría bezeichnet. ${ }^{30}$ Im Jahre 1542, im Rahmen der Leyes Nuevas, wurde die encomienda jedoch auf Tributzahlungen beschränkt. Die Leyes Nuevas hatten auch die räumliche und rechtliche Trennung im Rahmen der zwei Republiken zum Thema und schafften die naborías in ihrer bisherigen Form ab. ${ }^{31}$ Der repartimiento in der Form von Zuteilungen von Arbeitsdiensten wurde in Neuspanien 1632 abgeschafft, was allerdings nicht sofort umgesetzt

\footnotetext{
${ }^{28}$ Margarita Menegus, „La tradición indígena frente a los cambios liberales”: Revista de Indias, LXIX: 247 (2009), S. 137-156, hier S. 144. Erst 1811 wurden Indigene durch die rechtliche Gleichstellung zur alcabala verpflichtet. Siehe auch: Margarita Menegus Bornemann, „Mercados y tierras. El impacto de las reformas borbónicas en las comunidades indígenas": Jorge Silva Riquer / Antonio Escobar Ohmstede (Hg.), Mercados indígenas en México, Chile y Argentina. Siglos XVIII - XIX, México, D.F.: Inst. de Investigaciones Dr. José María Luis Mora, 2000, S. 17-50.

${ }^{29}$ Stavig, The World of Tupac Amaru, S. 224; Heraclio Bonilla, „Las formas cambiantes en la participación indígena en la independencia del Perú”: Heraclio Bonilla (Hg.), Indios, negros y mestizos en la independencia, Bogotá: Editorial Planeta Colombiana, 2010, S. 292-293.; Peter F. Guardino / Charles F. Walker, „The State, Society, and Politics in Peru and Mexico in the Late Colonial and Early Republican Periods”: Latin American Perspectives, 19: 2 (1992), S. 20-21.; Scarlett O’Phelan Godoy, Mestizos reales en el virreinato del Perú. Indios nobles, caciques y capitanes de mita, Lima: Fondo Editorial del Congreso del Perú, 2013, S. 267.

30 John M. Monteiro, „Labor Systems”: Victor Bulmer-Thomas / John H. Coatsworth / Roberto Cortés Conde (Hg.), The Cambridge Economic History of Latin America, Cambridge: Cambridge University Press, 2006, S. 191.

${ }^{31}$ Carlos Salvador Paredes Martínez, „Minería en transición. Repercusiones sociales por la extracción de minerales en Michoacán y su entorno en el temprano siglo XVI”: Sarah Albiez-Wieck / Hans Roskamp (Hg.), Nuevas investigaciones acerca del Michoacán antiguo, Zamora, Michoacán: Colegio de Michoacán, 2016, S. 184.
}

Jahrbuch für Geschichte Lateinamerikas | Anuario de Historia de América Latina 
wurde. ${ }^{32}$ In den nördlichen Minengebieten, einschließlich Michoacán, bestand er noch bis ins 18. Jahrhundert fort. ${ }^{33}$

In Peru war neben der encomienda vor allem der Arbeitsdienst in Form der sogenannten mita bedeutsam. Dieser Arbeitsdienst hatte vorspanische Vorläufer, wurde jedoch unter dem Vizekönig Toledo, der von 1569-1581 im Amt war, in seiner kolonialspanischen Form institutionalisiert. ${ }^{34}$ Danach hatte ein bestimmter Anteil der indigenen Bevölkerung zwischen 18 und 50 Jahren in regelmäßigen Abständen und in der Regel für sechs Monate Arbeitsdienste zu leisten. ${ }^{35}$ Es gab verschiedene mita-Dienste im Bereich der Landwirtschaft und der Minenarbeit, aber auch in Städten, die regional stark variierten. Die berüchtigte mita de minas für die Silberbergwerke in Potosí war nur von den Bewohnern der umliegenden Regionen zu erbringen. ${ }^{36}$

Weitere Arbeitsleistungen, meist servicios personales genannt, forderten die Kaziken, aber auch die encomenderos von den ihnen unterstellten indigenen Gemeinden. Auch die Kirche profitierte von Arbeitsdiensten, etwa in Form von Bauarbeiten an Kirchengebäuden oder Küchendiensten für den örtlichen Priester. Darüber hinaus erhielt die Kirche Geld- und Sachleistungen, die enger an den Tribut im eigentlichen Sinne gekoppelt waren. Diese dienten u.a. dem Unterhalt

\footnotetext{
${ }^{32}$ In der Recopilación findet sich folgendes Zitat, welches mit 1637 und 1668 datiert ist: „A pesar de haberse ordenado que cese el servicio personal de los indios y se tasse en dinero o frutos, hay algunas provincias en que duran todavía los servicios personales” „De los tributos”, Ley 25: Que se quiten las tassas de servicio personal, y se hagan en frutos, o especies.

${ }^{33}$ Monteiro, „Labor systems”, S. 190-201; María Concepción Gavira Márquez, „’Entiendan que desobedecen'. Estrategias de resistencia de la población indígena michoacana ante la coacción para el trabajo en las minas”: Carlos R. Ruiz Medrano (Hg.), Los otros rebeldes novohispanos. Imaginarios, discursos y cultura política de la subversión y la resistencia, San Luis Potosí: El Colegio de San Luís, 2015.

${ }^{34}$ Wightman, Indigenous Migration, S. 15.

${ }^{35}$ In vielen Teilen des Vizekönigreichs Peru war dies jeweils der siebte Teil der Bevölkerung, in der Audiencia de Quito jedoch der fünfte Teil: Udo Oberem, „Contribución a la historia del trabajador rural en América Latina. "Conciertos y Huasipungeros” en Ecuador”: Segundo E. Moreno Yánez / Udo Oberem (Hg.), Contribución a la etnohistoria ecuatoriana, Otavalo: IOA Instito Otavaleño de Antropología, 1981, S. 307; Nicolás Sánchez-Albornoz, „Mita, migraciones y pueblos. Variaciones en el espacio y en el tiempo. Alto Perú, 1573-1692”: Historia Boliviana, 3: 1 (1983), S. 31.

${ }^{36}$ Paul Charney, „Negotiating Roots. Indian Migrants in the Lima Valley During the Colonial Period": Colonial Latin American Historical Review, 5: 1 (1996), S. 1-20; Gil Montero, „Migración y tributación”, S. 39-65; Aude Argouse, Je le dis pour mémoire. Testaments d'indiens. Lieux d'une justice ordinaire. Cajamarca, Pérou, XVIIe siècle, Paris: Les Indes savantes, 2016, S. 14-15.
} 
der örtlichen Priester und wurden teilweise auch gemeinsam mit dem königlichen Tribut eingezogen. ${ }^{37}$

Eine weitere Institution, deren Bedeutung für die indigene Bevölkerung regional und zeitlich stark variierte, war der repartimiento oder reparto de mercancías. Es handelte sich dabei um einen Zwang zum Handel mit bestimmten Produkten, der auch Elemente eines Kreditsystems aufwies. Die Verfügbarkeit von Kapital hatte durchaus auch Vorteile für die indigene Bevölkerung, es gab jedoch auch massive Beschwerden gegen ausbeuterische Auswüchse des Systems. Der repartimiento-Handel diente spanischen Verwaltungsbeamten, insbesondere den corregidores und alcaldes mayores, auch zur Finanzierung ihres Ämterkaufs. ${ }^{38}$

\section{Tributkategorien im Vergleich: Von der Eroberung bis zu den bourbonischen Reformen}

Bei der Betrachtung des Tributsystems ist es zentral im Blick zu behalten, dass ein Tributzahler nicht mit einer Person gleichzusetzen ist. Vielmehr verstand man unter einem Tributzahler ein verheiratetes Paar. Ledige und Witwer wurden als halbe Tributzahler gezählt, als medios tributarios, und mussten auch nur die Hälfte zahlen. ${ }^{39}$ In den Quellen tauchen oft nur die Männer als Tributzahler auf; die Leistung, um den Tribut zu erbringen, wurde dessen ungeachtet gemeinschaftlich mit den Frauen erbracht. In den Tributlisten wurden aber teilweise auch Frauen und Kinder aufgeführt. ${ }^{40} \mathrm{Zu}$ zahlen hatte man in beiden Vizekönigreichen im

\footnotetext{
${ }^{37}$ Terán, „Geografía de los partidos“, S. 80.

38 Silke Hensel, Die Entstehung des Föderalismus in Mexiko. Die politische Elite Oaxacas zwischen Stadt, Region und Staat, 1786-1835, Stuttgart: Steiner, 1997, Bd. 49, S. 62-76; Brian R. Hamnett, Politics and Trade in Southern Mexico 1750 - 1821, Cambridge: Cambridge Universtiy Press, 1971 / 2008; Margarita Menegus Bornemann (Hg.), El repartimiento forzoso de mercancías en México, Perú y Filipinas, México, D.F.: Instituto de Investigaciones Dr José María Luis Mora; Centro de Estudios sobre la Universidad-UNAM, 2000; Guardino, The Time of Liberty, S. 27; Gil Montero / Zagalsky, „Colonial Organization“, S. 80-82; Raquel Gil Montero, „El tributo andino reinterpretado. El caso del corregimiento de Lípez”: European Review of Latin American and Caribbean Studies, 99: October (2015), S. 69-88, hier S. 73-74.

${ }^{39}$ Carta de Vasco de Puga al rey, por la que le informa la manera en que se tributaba en la Nueva España, 4 fs, s.f. ca. 1563-1565, AGI, MEXICO, 68, R.19, N.48.

${ }^{40}$ Dies wird in den königlichen provisiones so gefordert: „Real Provision acordada”, Que se Listen las Familias, y se pone la forma en que hàn de quedar distinguidos los Tributarios. Die Kinder wurden u.a. deshalb aufgeführt, da diese ja mit Erreichen des 18. Lebensjahres ebenfalls zu Tributzahlern wurden. Dies wird oft mit dem Vermerk
} 
Alter von 18 bis 50 Jahren. Handwerker, gleich ob indigen oder afrikanischstämmig, waren teilweise vom Tribut ausgenommen oder konnten ihn in Form der von ihnen erstellten Produkte erbringen. ${ }^{41}$

Die wichtigsten Gesetze für das 16. und 17. Jahrhundert sind in der Recopilación de Leyes de Indias enthalten, die 1680 zusammengestellt wurden. ${ }^{42}$ Von besonderem Interesse ist in diesem Zusammenhang das Buch 6, Titel 5 „De los tributos, y tassas de los Indios“, aber auch in anderen Büchern finden sich entsprechende Gesetze. Darüber hinaus gab es eine unüberblickbare Anzahl an Dekreten, Erlässen und Verordnungen verschiedener kolonialer Autoritäten, insbesondere von den Königen und Vizekönigen, die sich oft auf sehr spezifische, teils individuelle Fälle bezogen.

Indigene

Sowohl in Spanien als auch in den größeren staatlichen Einheiten in den Amerikas, d.h. den Reichen der Inka, Mexica ' (Azteken), Tarasken und Maya musste die breite Bevölkerung Abgaben zahlen und Arbeitsdienste leisten, während die Gruppe der „Adligen“ hiervon ausgenommen war. In Spanien hießen diese Abgaben pecho, und jene, die sie zahlen mussten, pecheros. In Hispanoamerika hingegen waren alle Spanier, auch jene, die vorher pecheros gewesen waren, von der Tributzahlung ausgenommen. Die Tributpflicht der indigenen Bevölkerung wurde mit ihrer Stellung als Vasallen der spanischen Krone begründet. Als solche genossen sie im Gegenzug die „Vorteile“ der spanischen Zivilisation, insbesondere der Christianisierung. Dabei wurde auch auf die angebliche Rechtmäßigkeit der Inbesitznahme Hispanoamerikas durch die spanische Krone, bestätigt durch die alexandrinische Bulle von 1493, Bezug genommen.

\footnotetext{
„próximos a tributar“ deutlich gemacht. Einige Beispiele für derlei Listen sind: Padrón de Tiripetío, 5 fs, 1700, AHCMO, Parroquial, Disciplinar, Padrones, Asientos, Caja 2181; hier werden Frauen separat aufgeführt; Padrón de tributarios del partido de Cajamarca, actualizada por el subdelegado juez real don Joaquín Miguel de Arnaco y el apoderador Fiscal don Bernardo Borié, 87 fs, 1803, ARC, Intendencia, Tributos, Leg. 1, Exp. 31; hier werden alle Familienmitglieder aufgeführt; ebenso hier: Padrón de los naturales de la cabecera de Zinzonza de la jurisdicción de Valladolid y demás instrumentos presentados por dichos naturales, 26 fs, 1722, AHMM, Hacienda, Caja 7-B, Exp. 3.

${ }^{41}$ Gibson, Los aztecas bajo, S. 199-200; Covey / Elson, „Ethnicity, Demography”, S. 320-321; „De los tributos”, Ley 7: Que los indios solteros tributen de 18 años, sino estuviere introducido otro tiempo.

42 Recopilación de leyes de los reinos de las Indias, Madrid, 1680, http://www.leyes.congreso.gob.pe/leyes_indias.aspx [17-01-2017].
} 
Ein weiteres zentrales Argument der Legitimierung war die ordnungsgemäße Abtretung der Territorien durch die letzten vorspanischen Herrscher, ${ }^{43}$ wodurch die Krone auch deren Recht auf die ihnen zustehenden Tribute und Arbeitsleistungen übernommen habe. ${ }^{44}$ Damit wurden die Tributzahlungen an die Spanier in eine Linie mit den vorspanischen Tribut- und Arbeitsleistungen gestellt, und werden auch in der Forschung als ursprünglich amerikanische und nicht als spanische Institution bezeichnet. ${ }^{45}$ Auch in der praktischen Umsetzung der Tributeintreibung stützten sich die Spanier anfangs auf vorspanische Praktiken, was etwa die Periodizität und den Umfang der Abgaben betraf. Auf die Tatsache, dass die indigene Bevölkerung bereits in vorspanischer Zeit ihren Herrschern Tribut zahlte, wird in Quellen und in der Gesetzgebung immer wieder legitimierend Bezug genommen. ${ }^{46}$ Die Eintreibung des Tributs durch indigene Adlige wurde noch sehr lange fortgeführt, was oft dazu führte, dass nicht alle Tributeinnahmen an die Spanier abgegeben wurden. Mit der Zeit wurde die Tributeintreibung stärker an die spanischen Bedürfnisse angepasst, sowohl was die Abläufe, als auch was die Höhe anging. Außerdem wurde der Tribut mehr und mehr monetarisiert und nicht länger in Form von Produkten erbracht, verstärkt nach $1570 .{ }^{47}$ Allerdings war diese Entwicklung nicht linear, und teilweise wurde aufgrund des Rückgangs in der landwirtschaftlichen Produktion die Zahlung in Sachmitteln wieder zugelassen; auch wurden einige Grundnahrungsmittel, wie etwa Mais, sehr lange als Tribut in Produktform abgeliefert. ${ }^{48}$ Die Höhe des zu erbringenden Tributes wurde für indigene Gemeinden als Ganzes festgesetzt und die Kaziken bzw. gobernadores waren für diesen kollektiven Tribut insgesamt gegenüber den höheren spanischen Verwaltungsebenen verantwortlich;

\footnotetext{
${ }^{43}$ Auch in der Karibik mussten die Indigenen schon Tribut zahlen; laut Miranda, El tributo indígena, S. 38-39 fand die erste Tributzahlung auf Anordnung von Kolumbus in Santo Domingo statt, nach dem ersten Aufstand der dortigen Indigenen. Die erste königliche Anordnung für Tributzahlungen stammt von 1501. Siehe auch Fonseca / Urrutia, Historia general, S. 411-412.

${ }^{44}$ Charles Gibson, „Las sociedades indias bajo el dominio español”: Leslie Bethell (Hg.), Historia de America Latina. América Latina colonial. Poblacion, sociedad y cultura, Barcelona: Critica, 2000, S. 157-188, S. 171; Fonseca / Urrutia, Historia general, S. 651-652.

${ }^{45}$ Carlos Marichal, „Money, Taxes, and Finance”: Victor Bulmer-Thomas / John H. Coatsworth / Roberto Cortés Conde (Hg.), The Cambridge Economic History of Latin America, Cambridge: Cambridge University Press, 2006, S. 434-435.

${ }^{46}$ Z.B. Cartas y expedientes de virreyes de Perú vistos o resueltos en el Consejo, 28.4.1561-31.04.1562, AGI, Lima 28A, microfilm ED - 61-/R1, imágenes 112-136.

${ }^{47}$ Loza, „¿Estatuto fiscal contra”, S. 388; Noack, „Die Visitation“, S. 224-225.

${ }^{48}$ Fonseca / Urrutia, Historia general, S. 496 (36).
} 
anfangs variierte die Höhe des zu erbringenden Tributs zwischen den verschiedenen Gemeindemitgliedern.

Nicht alle Indigenen mussten Tribut zahlen: Kaziken und ihre erstgeborenen Söhne waren ausgenommen, ebenso die Inhaber von Ämtern im weltlichen und kirchlichen Bereich während ihrer Amtszeit, sowie Kranke. ${ }^{49}$ Laut verschiedener Gesetze vom Beginn des 17. Jahrhunderts waren indigene Frauen, auch ledige Frauen und Witwen, von der Tributpflicht ausgenommen. ${ }^{50}$ Des Weiteren gab es verschiedene regionale Ausnahmen in Neuspanien, beispielsweise für Tlaxcala, Santa Fe de la Laguna in Michoacán und Grenzregionen im Norden, etwa Nueva Vizcaya. ${ }^{51}$

Die Tributzahlungen von Indigenen sind in Zusammenhang mit deren Landbesitz zu sehen. Als Mitglied eines pueblo de indios hatte man Zugriff auf das gemeinschaftlich besessene Land, dessen Bearbeitung die Erwirtschaftung von Überschüssen und damit die Zahlung von Tribut ermöglichen sollte. Dies war auch einer der Gründe dafür, dass die Gesetzgebung versuchte, indigenes Land vor spanischem Zugriff zu schützen - auch wenn das im Einzelnen oft nicht gelang bzw. gelingen sollte. ${ }^{52}$

Die tributzahlende Bevölkerung, auch jene der encomiendas, wurde in Listen, sogenannten matrículas eingetragen, in denen auch die Höhe des

49 „De los tributos”, Ley 18: Que los caciques, y sus hijos mayores no paguen tributo, Ley 20; "Real Provision acordada para la nueva cuenta y visita personal de los naturales y demas Tributarios. [Disposiciones emitidas entre la Recopilacion indiana de 1681 y 1766, que permanecieron como 'Adiciones' de las legislaciones posteriores]. AGN, Tributos, vol. 23, exp. 13, fs. 345- 355”: Martha Terán (Hg.), Tributos tardíos de la Nueva España. Programa interactivo, México, D.F.: Autos, 2016, S. 104, 105, 110.

50 „De los tributos”, Ley 19: Que las indias no paguen tassa; Fonseca / Urrutia, Historia general, S.418 (párrafo 19).

${ }^{51}$ Fonseca / Urrutia, Historia general, S. 429 (párrafo 44). Die Ausnahme für Tlaxcala war in der Unterstützung der Spanier bei der Eroberung begründet; die Grenzregionen unterlagen Ausnahmen zur Stabilisierung und Sicherung gegen (halb)nomadische, noch nicht eroberte Indigene. Die Freistellung von Santa Fe de la Laguna wurde von Bischof Vasco de Quiroga durchgesetzt und hielt sich mindestens bis zur Mitte des 18. Jahrhunderts. Siehe hierzu auch: Real provisión para que los naturales del pueblo de Santa Fe paguen tributo o muestren el título que los releva del pago, 12 fs, 1713, AGNM, Indiferente Virreinal, Caja 1876, Exp. 12; Autos que pidio el señor fiscal a Juan Francisco de la Paz, Joseph Rodríguez Gardo, para indagar las causas por los que los naturales de Santa Fee no pagan tributo, 24 fs, 1753, AGNM, Indiferente Virreinal, Caja 4728, Exp. 83; Clara García Ayluardo, Las reformas borbónicas, 1750-1808, México, D.F.: CIDE, 2010, Bd. 1, S. 77.

${ }^{52}$ Für den Fall Cajamarca im 17. Jahrhundert, vgl. Sarah Albiez-Wieck, „Indian Migrants Negotiating Belonging. Peticiones de Cambio de Fuero in Cajamarca, Peru, 17th-18th century": Colonial Latin American Review, (unveröffentlicht); Argouse, Je le dis. Für Pátzcuaro AHCP, Sobre tierras de.

Jahrbuch für Geschichte Lateinamerikas | Anuario de Historia de América Latina 
Tributs, die tasa, festgehalten wurde. ${ }^{53}$ Diese wurden immer wieder in den sogenannten retasas aktualisiert; frühestens alle drei Jahre, meist jedoch in viel größeren Abständen, um gestorbene, volljährig gewordene und migrierte Tributzahler zu berücksichtigen ${ }^{54}$ Diese wurden zumeist im Rahmen von Visitationen, sogenannten visitas, oder, im wiederholten Falle, revisitas, erhoben. Diese wurden von kolonialen Beamten durchgeführt, die sich dabei aber oft auf die Angaben der zuständigen indigenen Kaziken und gobernadores verließen. Dieses Verfahren wurde mit einer real cédula ${ }^{55}$ aus dem Jahre 1536 für Neuspanien formalisiert, dauerhaft institutionalisiert und mit den Leyes Nuevas auch auf andere Gebiete, einschließlich Peru, ausgedehnt. ${ }^{56}$ Kürzlich eroberte und in congregaciones umgesiedelte Indigene sollten in den ersten zwei, später zehn Jahren, zur Hälfte oder gänzlich von der Tributpflicht befreit sein; des Weiteren gab es eine Reduzierung im Fall von Epidemien, Dürren oder ähnlichen Schicksalsschlägen. ${ }^{57}$ Auch insgesamt ist die Gesetzgebung auf den Schutz der indigenen Bevölkerung als (unmündige) Vasallen der Krone ausgerichtet - wobei jedoch viele Gesetze nicht oder nur in begrenztem Umfang angewendet wurden.

Die Höhe der Tributzahlungen wurde von spanischen Kronbeamten festgesetzt. Sie hatten die Vorgabe, die Höhe an die Möglichkeiten der indigenen Bevölkerung anzupassen und lediglich einen

\footnotetext{
${ }^{53}$ Ibidem, Ley 48: Que ningun encomendero lleve sus tributos sin estar tassados los yndios, y no perciva otra cosa.

${ }^{54}$ Ibidem, Ley 60. Que en las retassas se declare la cantidad cierta, que han de tributar los indios; ibidem, Ley 62: Que la nueva visita, o cuenta, no suspende la paga de los corridos.; ibidem, Ley 59: Que no se retassen indios de la Corona Real, hasta despues de tres años de la ultima tassa.; ibidem, Ley 53: Que el Oidor Visitador haga las cuentas, y tassas. Fonseca / Urrutia, Historia general, S. 436-37 (párrafo 62).

55 José Joaquin Real Díaz, Estudio diplomático del documento indiano, Sevilla: Dirección de Archivos Estatalis, 1970, S. 225-226 definiert real cédula als „documento eminentemente dispositivo y se convierte en el vehículo normal de relación entre el rey y las autoridades indianas. Encierra generalmente un precepto de gobernación. [...] Queremos resaltar el acentuado carácter de documento dispositivo de la real cédula, es decir, que la actio cobra realidad y efectividad en el momento de su conscriptio y que no existió con independencia o anterioridad a su redacción.”.

${ }^{56}$ Miranda, El tributo indígena, S. 93, 98-101.

${ }^{57} \mathrm{Zu}$ der Anzahl der Jahre: „De los tributos, y tassas de los Indios. Libro 6, Título V”, Recopilación de leyes de los reinos de las Indias, Madrid, 1680: Ley 2: Que los indios reducidos, y congregados a poblaciones, paguen por dos años la mitad del tributo; ibidem, Ley 3: Que los indios infieles reducidos a nuestra Santa Fe, por la predicacion, no sean encomendados, tributen, ni sirvan por diez años; Fonseca / Urrutia, Historia general, S. 486 (párrafo 18). Bezüglich der Epidemien und Dürren: „De los tributos”, Ley 45. Que haviendo peste en pueblos de indios, se moderen las tasas; Fonseca / Urrutia, Historia general, S. 435 (párrafo 59).
} 
„moderaten“ Tribut einzufordern. Die festgesetzten Beträge variierten regional und zeitlich stark und allgemeine Angaben sind sehr schwer zu finden. ${ }^{58}$ Einige Anhaltspunkte gibt es jedoch. Diese zeigen, dass die Tributzahlungen in Neuspanien deutlich unter denen in Peru lagen: Für das Jahr 1678 geben Fonseca und Urrutia für Neuspanien zwei pesos und einen halben real an. Pedro Valdés, Contador de Tributos gibt für die Zeit vor den bourbonischen Reformen zwei sich widersprechende Beträge an: 20 reales und zwei pesos. ${ }^{59}$ Marichal nennt als durchschnittlichen Wert für ganz Hispanoamerika zwei pesos. ${ }^{60}$ Allerdings scheint in Peru, zumindest in der Audiencia de Charcas, der tatsächliche Betrag deutlich höher gelegen zu haben. Sánchez Albornoz nennt für das Ende des 17. Jahrhunderts eine Tributhöhe von mindestens sieben pesos. ${ }^{61}$ Wenn man den Anteil der Einnahmen aus Tributen an den Gesamteinnahmen der königlichen Krone betrachtet, fällt auf, dass dieser bis zum Beginn des 18. Jahrhunderts vergleichsweise gering war; er betrug unter $10 \%$. Laut Klein war die steuerliche Belastung der Bevölkerung Spanisch-Amerikas insgesamt niedriger als die der Bevölkerung im spanischen Mutterland und lag ein wenig unter der in französischen und etwas über der in englischen Kolonien. ${ }^{62}$ Doch auch wenn gerade in der ersten Hälfte der Kolonialzeit die Arbeitsdienste vermutlich im Vordergrund standen, wurden auch Tributzahlungen von den Indigenen durchaus als belastend angesehen. Es gab im 17. Jahrhundert zahlreiche Eingaben der indigenen Tributeinzieher, die sich über die Höhe der Tributzahlungen beschwerten. Da sie die ausstehenden Tribute nicht bezahlen konnten, wurden sie teilweise inhaftiert. Einer der Kaziken aus Cajamarca, Francisco Tanta Guatay, musste zu Beginn des 17. Jahrhunderts sogar ein Grundstück mitsamt Haus verkaufen, um die Tribute der ihm unterstehenden Indigenen bezahlen zu können. ${ }^{63}$ Dass Kaziken nicht für den

\footnotetext{
${ }^{58}$ Selbst in der Recopilación gibt es keine einzige allgemein angegebene Tributhöhe für Neuspanien und Peru, auch viele andere Autoren weisen auf die enormen Unterschiede hin, z.B. Gibson „Las sociedades indias“, S. 172-173.

${ }^{59}$ Propuesta hecha por el contador de tributos sobre las tasaciones hechas entre los indios de pueblas, mulatos e indios laborios, para que se haga una distinción de tributarios, firma don Pedro Valdés Contaduría de Real Hacienda, 1762, 12 fs, 23.01.1762, f. 2vs, AGNM, Indiferente Virreinal, Caja 5670, Exp. 56, f. 4vs, f. 5vs.

${ }^{60}$ Fonseca / Urrutia, Historia general, S. 428-429 (párrafo 43,44,45); Marichal, „Money, Taxes, and Finance”, S. 435.

${ }^{61}$ Sánchez Albornoz, Indios y tributos, S. 92.

${ }^{62}$ Klein, The American Finances, S. 20-22, S. 108.

63 Don Francisco Tanta Guatay, Cacique Principal del pueblo de Chota, solicitando al corregidor de Cajamarca le otorgue licencia para vender una casa y solar y poder cancelar los tributos que debían los indios de las tres guarangas, 3 fs, 11.09.1609, ARC, Corregimiento, Causas Ordinarias, Tributos, Leg. 01, Exp. 14.
} 
vereinbarten Tribut aufkommen konnten, lag oft auch daran, dass viele der ihnen untergebenen Indigenen migriert waren, um Tributzahlung und Arbeitsdiensten zu entgehen. Dies bedeutete in der Regel auch eine deutlich höhere Belastung für die zurückgebliebenen Indigenen. Ähnliche Gründe für die Unfähigkeit, die geforderten Tributzahlungen zu entrichten, wurden zu Beginn des 17. Jahrhunderts von indigenen Adligen in Michoacán angegeben. Sie wiesen auch darauf hin, dass sie nicht die Macht besaßen, sich gegenüber den säumigen Tributzahlern durchzusetzen. Im späten 16., aber vor allem im 17. Jahrhundert, gab es sowohl in Michoacán als auch in Cajamarca immer wieder Personen, die versuchten, die Tributkategorie des „Indio“ zu verlassen um von der Tributpflicht entbunden zu werden und stattdessen als Mestize, Spanier, adliger Indigener oder als „Migrant“ (s.u.) anerkannt zu werden. Dabei wurden Tribute und Zwangsarbeitsdienste in Michoacán in der Regel als Hand in Hand gehende Belastungen dargestellt. ${ }^{64}$ In Cajamarca wurde in vergleichbaren Fällen aus dem 17. Jahrhundert stärker zwischen der mita und verschiedenen zu zahlenden Tributhöhen differenziert. ${ }^{65}$

Eingezogen wurde der Tribut in den Dörfern, die direkt der Krone unterstellt waren, von den örtlichen indigenen Kaziken bzw. gobernadores und ihren Helfern, die üblicherweise ebenfalls adelig waren und die u.a. als mandones bezeichnet wurden. In Peru waren die Kaziken jeweils der korporativen Verwandtschaftsgruppe des ayllu vorgestellt und trieben für diese Einheiten den Tribut ein. In Neuspanien scheinen zumindest im 16. Jahrhundert auf dem ehemaligen Gebiet des Aztekenreichs die Anführer der Verwandtschaftsgruppen der calpulli eine ähnliche Funktion übernommen zu haben. ${ }^{66}$ In den Dörfern, die einem encomendero zugeordnet waren, war dessen Verwalter für die Tributeintreibung zuständig. ${ }^{67}$ Der corregidor, die den Kaziken

${ }^{64}$ Z.B. Francisco de Rivera, indio natural de la Villa de Zamora residente en Uruapan, ante el Teniente de alcalde mayor Matias de Castro, solicita que no se le exija el pago del tributo ni servicios personales, por ser descendiente de reyes y caciques, 4 fs, 1640, AHMM, Hacienda, Caja 3, Exp. 6-C.

65 Z.B. Francisco Hernando y Joseph Lorenzo, indios forasteros originarios de la ciudad de Chachapoyas, solicitando ser exonerados del pago de tributos en el pueblo de Santiago de Chuco, 7 fs, 12.04.-21.05.1680, ARC, Corregimiento, Causas Ordinarias, Tributos, Leg. 02, Exp. 25. Vgl. auch den Abschnitt über “migrantische” Kategorien.

${ }^{66}$ Eike Hinz / Claudine Hartau / Marie-Luise Heimann-Koenen, Aztekischer Zensus. Zur indianischen Wirtschaft und Gesellschaft im Marquesado um 1540; aus dem "Libro de tributos“ (Col. ant. ms. 551) im Archivo Histórico, México, Hannover: Verlag für Ethnologie, 1983, S. XLII.

${ }^{67}$ Z.B. El Protector de Naturales D. Pedro de Chavez Tarisca en nombre D. Matheo Baptista, cacique y cobrador de tributos de los indios del ayllu de Lluycho del pueblo de Cajabamba solicitando una requisitoria para que los jueces de Trujillo cobren a los indios 
übergeordnete regionale Autorität, war in der Regel für die Zusammenführung der Tribute und die Übergabe an die königlichen Steuerbeamten zuständig. Aus diesen Einnahmen speiste sich sein Gehalt, weshalb er auch ein großes Eigeninteresse an dieser Aufgabe hatte. ${ }^{68}$ Üblich war der Einzug der Tribute alle vier Monate, zu den sogenannten tercios. ${ }^{69}$ Nach Zahlung der Tribute erhielten die Zahlenden eine Quittung, eine recibo de tributo, die ein wichtiges rechtliches Dokument war, welche in Unklarheit bei der Kategorisierung einer Person immer wieder herangezogen wurde. ${ }^{70}$

Diese Regeln wurden jedoch nicht immer beachtet, etwa was das Alter der Tributzahler anging. ${ }^{71}$ Korruption und Unterschlagung von Geldern gab es auf allen Ebenen der Tributeintreibung, von den Kaziken, die einen Teil ihrer Untergebenen versteckten oder nicht angaben, bis zu den königlichen Steuerbeamten. ${ }^{72}$

\section{Afrodescendientes}

Die Tributpflicht der afrodescendientes wurde unter anderem damit begründet, dass auch in den afrikanischen Königreichen, aus denen sie oder ihre Vorfahren stammten, eine Tributpflicht bestanden habe. Allerdings wurden sie laut Grewe zumindest ursprünglich nicht wie Indigene als Vasallen der spanischen Krone angesehen. Vielmehr wurde die Einführung ihrer Tributpflicht „als Rekompensation dafür, dass Afroamerikaner auf königlichem Boden in Freiheit und Frieden leben durften“"73 begründet.

José Romero y Felix de la Cruz residentes en dicha ciudad, 4 fs, 15.03.1665, ARC, Corregimiento, Protector de Naturales, Tributos, Leg 01.

${ }^{68}$ Miranda, El tributo indígena, S. 345-347.

${ }^{69}$ Gibson, Los aztecas bajo, S. 203-204; AGNM Instrucciones hechas; Mandamiento del virrey que el capitan Don Fernando de Deza y Ulloa juez y contador y administrador general de los tributos e servicios reales desta Nueva España hace saber a los alcaldes mayores, corregidores y otras justicias, 3 fs, 1684, AHMM, Gobierno, Caja 1, Exp. 15. Terán, „Geografía de los”, S. 82 weist darauf hin, dass es auch Orte gab, in denen der Tribut bis zum Ende der Kolonialzeit jährlich eingezogen wurde.

${ }^{70}$ Siehe hierzu Albiez-Wieck, „Indian Migrants Negotiating”; Fernando Granados, „Pasaportes neoclásicos”, S. 371.

${ }^{71}$ AGI „Nuevo orden”.

${ }^{72}$ Carta del oidor Alonso de Zurita al rey, en la que le informa sobre los tributos de los naturales, y de los fraudes que había en las cuentas, por parte de los oficiales de Hacienda, 2 fs, 04.03.1561, AGI, Mexico, 68, R.20, N.49bis.

${ }^{73}$ Grewe, Ethnizität, Staatsbürgerschaft und Zugehörigkeit, S. 38. Grewe analysiert die Stellung der afrikanischstämmigen im Vergleich zur indigenen Bevölkerung vor 
Die freie afrikanischstämmige Bevölkerung wird in der kolonialen Terminologie meist als negro (libre) oder mulato bezeichnet. wobei es noch weitere rassifizierte Unterteilungen der sogenannten castas gab, etwa lobo und coyote in Neuspanien und cholo und zambo/zambaigo in Peru. Diese Unterscheidungen spielten für die Tributpflicht in Peru eine größere Rolle als in Neuspanien.

Afrodescendientes waren ab 1573/74 gesetzlich zu Tributzahlungen verpflichtet und lediglich befreit, wenn sie in einer Miliz dienten. ${ }^{74}$ Allerdings herrscht in der Forschung Uneinigkeit über die Anwendung dieses Gesetzes, insbesondere in Peru. Vinson und Pollack, die regional eher zu Neuspanien gearbeitet haben, sehen die Tributzahlung als allgemeine Pflicht für ganz Hispanoamerika an, ${ }^{75}$ die jedoch laut Castañeda García nicht immer angewandt wurde. ${ }^{76}$ Für Peru weist Ares Queija auf die großen Schwierigkeiten und Widerstände bei der Umsetzung hin. ${ }^{77}$ Auch Hünefeldt und Mansilla Escobedo sind der Ansicht, dass in Peru die afrikanischstämmige Bevölkerung, auch wenn sie nicht als Milizionär tätig war, ihre Befreiung von der Tributpflicht verhandeln konnte. ${ }^{78}$ Ramos Gómez und Ruigómez Gomez unterstreichen für die Audiencia de Quito, dass die Einkünfte aus

allem für das 18. und frühe 19. Jahrhundert, beschäftigt sich jedoch auch kurz mit dem 16. Jahrhundert.

74 „De los tributos”, Ley 8: Que los hijos de negros, e indias, havidas en matrimonio, tributen como indios.; „De los Mulatos, Negros, Berberiscos, é hijos de Indios. Libro 7, Título V”, Recopilación de Leyes de los Reinos de las Indias, Madrid, 1680, Ley 1: Que los negros, y negras, mulatos y mulatas libres paguen tributo al rey; ibidem, Ley 2: Que los hijos de Negros libres, o esclavos, havidos en matrimonio con Indias, deven tributar.; Sumario de las ocasiones y raíces que an tenido toda manera de estados de la gente desta tierra para tener algunas quejas del virrey, s.f. ca. 1570, AGI, Lima 28 A - ED - 61-/R2, imágenes 200-203. Für Neuspanien weisen Fonseca / Urrutia, Historia general, S. 485 (párrafo 17) als Beginn der Tributzahlung auf eine Real Cédula von 1574 hin, schreiben aber auch (S. 487 (párrafo 20)), dass die afrikanischsstämmige Bevölkerung bis 1580 befreit war; Hünefeldt, „Esclavitud, percepciones raciales”.

${ }^{75}$ Ben Vinson III., Bearing Arms for His Majesty. The Free-colored Militia in Colonial Mexico, Stanford: Stanford University Press, 2001, S. 132; Pollack, „Hacia una historia”, S. 92-93.

${ }^{76}$ Rafael Castañeda García, „Hacia una sociología fiscal. El tributo de la población de color libre de la Nueva España, 1770-1810”: Fronteras de la Historia, 19: 1 (2014), S. 152-173, hier S. 157.

77 Berta Ares Queija, „Mestizos, mulatos y zambaigos (Virreinato del Perú, siglo XVI)”: Berta Ares Queija / Alessandro Stella (Hg.), Negros, mulatos, zambaigos. Derroteros africanos en los mundos ibéricos, Sevilla: Escuela de Estudios Hispanoamericanos, 2000, S. 87.

${ }^{78}$ Hünefeldt, „Esclavitud, percepciones raciales”, S. 272; Mansilla Escobedo, „El tributo de los zambaigos”, S. 53. 
Tributen von freien afrodescendientes minimal waren. ${ }^{79}$ Die von mir untersuchten Dokumente aus Cajamarca im Norden Perus, die vorrangig aus dem 17. und 18. Jahrhundert stammen, weisen gleichwohl vereinzelt darauf hin, dass die freie afrikanischstämmige Bevölkerung durchaus Tribut entrichtete. ${ }^{80}$ In Neuspanien zahlte die freie afrikanischstämmige Bevölkerung spätestens im 17. Jahrhundert größtenteils Tribut, wie ich mehreren Quellen aus Zentralmexiko und Michoacán entnehmen konnte. ${ }^{81}$ Laut dem Contador de Tributos von Neuspanien betrug dieser für verheiratet Tributzahler zwei pesos. ${ }^{82}$

Im Gegensatz zur Indigenen war die freie afrikanischstämmige Bevölkerung nicht zu Arbeitsdiensten, wie etwa der mita verpflichtet. Obwohl dies die Tributkategorie des Mulatten als attraktiver erscheinen lässt und daher auch durchaus von einigen Indigenen, insbesondere in Cajamarca, angestrebt wurde, ${ }^{83}$ stand die afrikanischstämmige Bevölkerung in der sozialen Hierarchie unter den Indigenen. Daher gibt es, insbesondere in Michoacán einige Fälle, in denen sich diese empört dagegen wehrten, als Mulatten kategorisiert zu werden. ${ }^{84}$

\footnotetext{
${ }^{79}$ Luis Ramos Gómez / Carmen Ruigómez Gómez, „Una propuesta a la corona para extender la mita y el tributo a negros, mestizos y mulatos. (Ecuador, 1735-1748)": Revista Complutense de Historia de América, 25 (1999), S. 100-101.

${ }^{80}$ So gab es etwa Anfang des 17. Jahrhunderts einen Kaziken, Diego Astopilco, der u.a. für die Eintreibung der Tribute der Mulatten zuständig war: Rafael Juan Olivito en nombre de los jueces oficiales Reales de Trujillo, integrantes de la comisión, para el cobro de tributos de la Real Hacienda ordenando que el Cobrador Don Diego Astopilco cancele los tributos del año 1619 que corresponden a los indios forasteros y yanaconas, 35 fs, 19.08.1622-12.09.1623, f. 13-14r, ARC, Corregimiento, Causas Ordinarias, Tributo, Leg. 01, Exp. 23.

${ }^{81}$ Siehe z.B. AHMM Mandamiento del virrey; AGNM Instrucciones hechas por, f. 12; Expedientes que tratan sobre tributos de negros y mulatos libres, e indios laboríos. Cobranza, rezagos, 215 fs, 1655, AGNM, Indiferente Virreinal, Caja 3138, Exp. 26; El Alcalde Mayor Gregorio Romano Altamirano, manda se pregone la visita general que hará en la jurisdicción para el cobro de alcabalas y tributos, 9 fs, 1640, f. 5-9vs, AHMM, Hacienda, Caja 1, Exp. 9-A.

${ }^{82}$ Propuesta hecha por, f. 3r.

${ }^{83}$ Dies war etwa der Fall bei Andrés Fernández Pizarro aus Cajamarca, der erfolgreich versuchte als Mulatte und nicht als indio forastero anerkannt zu werden: Andrés Fernández Pizarro, vecino de la villa de Cajamarca, solicitando ser declarado como mulato y no como indio forastero, 6 fs, 24.05.1678-20.01.1679, ARC, Corregimiento, Causas Ordinarias, Leg. 83, Cat. 1713. Siehe hierzu auch: Albiez-Wieck, „Indian Migrants Negotiating”.

${ }^{84}$ Der indio laborío Victoriano Alvarado etwa bezeichnete seine Kategorisierung als Mulatte als schädlich und wollte keinesfalls, dass dieser Schaden wie eine Ansteckung an seine Nachfahren weitergegeben würde: Victoriano Alvarado, indio laborío residente de esta ciudad, sobre que se le borre de la matrícula de mulatos y se le pase a la de indios, fs. 390-401, 26.09.1808, AGNM, Real Hacienda, Tributos, Vol 18, Exp. 19.
} 
Afrikanischstämmige ledige Frauen mussten laut der Rechtslage wohl Ende des 16. und im 17. Jahrhundert Tribut entrichten. ${ }^{85}$ Zumindest forderte dies eine instrucción ${ }^{86}$ des Vizekönigs Gaspar de Zuñiga, Conde de Monterrey, aus dem Jahre $1598 .{ }^{87}$

\section{„Migrantische“ Tributkategorien: forasteros, yanaconas, vagos und laboríos}

Sowohl in Peru als auch in Neuspanien genoss die Bevölkerung grundsätzlich ein Recht auf Freizügigkeit. ${ }^{88}$ Bezüglich der internen Migration der indigenen Bevölkerung nahm die spanische Krone jedoch eine widersprüchliche Haltung ein, die sich in der Gesetzgebung widerspiegelt. ${ }^{89}$ Einerseits wollte sie, dass die indigene Bevölkerung getrennt von den Spaniern in ihren Gemeinden lebte, um dort ihr Land $\mathrm{zu}$ bearbeiten und Tribut $\mathrm{zu}$ zahlen, andererseits war die indigene Arbeitskraft in Minen, auf Haciendas und in Textil- und Zuckermühlen, aber auch als Hausangestellte in der Stadt, dringend nötig. Die Arbeitsformen, die dort praktiziert wurden, befanden sich in einer Grauzone zwischen Sklaverei und freier Lohnarbeit und verhinderten die Freizügigkeit de facto oft.

\footnotetext{
${ }^{85}$ Menegus Bornemann, „Alcabala o tributo”, S. 116; Castañeda García, „Hacia una sociología”, S. 158.

${ }^{86}$ Real Díaz, Estudio diplomático, S. 234, schreibt: „instrucciones van dirigidas a personas determinadas, no por ellas mismas, sino por el oficio o cargo que desempeñan. Documentan un programa de actuación, de aquí el dispositivo esté dividido en capítulos, cada uno de ellos ordenando un asunto concreto.”

${ }^{87}$ Instrucciones hechas por Gaspar de Zuñiga, conde de Monterrey y presidente de la Audiencia, acerca del cobro de tributos y servicio de pueblos, mulatos y negros libres e indios laborios, 2 fs, 1623, f. 1vs-2r, AGNM, Indiferente Virreinal, Caja 6033, Exp. 02.

${ }^{88}$ Zentral ist diesbezüglich Silvio Zavala, „La libertad de movimiento de los indios de Nueva España”: Elías Trabulse (Hg.), Silvio Zavala. Estudios acerca de la historia del trabajo en México. Homenaje del Centro de Estudios Históricos a Silvio Zavala, México, D.F.: El Colegio de México, Centro de Estudios Históricos, 1988, S. 213-251.

${ }^{89}$ In der Recopilación sind die Aussagen folgender Gesetze diesbezüglich widersprüchlich: „De los tributos”, Ley 6: Que se cobre la tassa de los indios, que estuvieren fuera de sus reducciones indios fuera de reducciones; „De los Indios. Libro 6, Título I”, Recopilación de leyes de los reinos de las Indias, Madrid, 1680, Ley 12: Que los indios se puedan mudar de unos lugares a otros, erlauben die Freizügigkeit mit wenigen Einschränkungen; „De las reducciones”, Ley 18: Que ningun indio de un pueblo se vaya a otro; ibidem, Ley 19: Que no se de licencia a los indios para vivir fuera de sus reducciones, die im Zusammenhang mit den congregaciones stehen, schränken die Freizügigkeit stark ein.
} 
Die Indigenen, die außerhalb indigener Gemeinden arbeiteten, mussten laut verschiedener, in der Recopilación gesammelter Gesetze, einen „moderaten“ Tribut zahlen. Diese Gesetze stammen vom Ende des 16. und Beginn des 17. Jahrhundert und weisen darauf hin, dass die dort arbeitende Bevölkerung vorher keinen Tribut gezahlt hatte. ${ }^{90}$ In den Gemeinden, die diese Personen verlassen hatten, wurden sie in den Tributlisten als Abwesende, als ausentes, eingetragen, um zu vermeiden, dass die anwesende Bevölkerung für sie den Tribut mitzahlen musste. ${ }^{91}$ Nach zehn Jahren sollten sie dann zu ausentes absolutos erklärt werden, da ihre Rückkehr nicht mehr zu erwarten war. ${ }^{92}$ Allerdings wurden diese Änderungen erst nach einer retasa wirksam, was teilweise zu erheblichen Zahlungsproblemen führte. Auch wurden die Abwesenden nicht immer als ausentes geführt, sondern zahlten teilweise ihren Tribut weiter regulär an ihre Ursprungsgemeinde. Die Kategorisierung der Migranten ${ }^{93}$ unterschied sich in Neuspanien und Peru deutlich, weshalb ich diese im Folgenden getrennt darstellen werde.

In Peru war die wichtigste "migrantische" Kategorie die des indio forastero, die keine vorspanischen Vorläufer hatte. Sie bezeichnete in der Regel jene Indigenen, die ihre Gemeinden verließen und in andere Gemeinden zogen, sowie deren Nachkommen. Die Motivation, forastero $\mathrm{zu}$ werden, scheint oft darin gelegen $\mathrm{zu}$ haben, den hohen Tributforderungen und dem mita-Dienst zu entkommen. Die forasteros waren zahlenmäßig und gesellschaftlich sehr bedeutsam; in einigen Orten stellten sie bis zu 80\% der Bevölkerung. ${ }^{94}$ Besonders für den Süden Perus ist das Phänomen der forasteros recht gut untersucht, ${ }^{95}$

90 „De los tributos”, Ley 9: Que los indios, que trabajaren en minas, huertas, y otras haciendas, tributen; ibidem, Ley 10: Que los indios ocupados en estancias, obrajes, y otros exercicioes, tributen para el rey.

${ }^{91}$ Ibidem, Ley 15: Que los indios no sean agraviados en tributar por muertos, y ausentes.

92 „Artículos 124-141 de la Real ordenanza para el establecimiento é instrucción de intendentes de exército y provincia en el Reino de la Nueva España, de órden de su Majestad. Madrid, 1786, S. 145-169”: Martha Terán (Hg.), Tributos tardíos de la Nueva España. Programa interactivo, México, D.F., 2016, Artículo 21.

${ }^{93}$ Es migrierten zwar auch Frauen; da diese jedoch i.d.R. nicht als eigenständige Tributzahlerinnen auftauchten, wird in der Folge zumeist von Tributkategorien für Männer die Rede sein.

${ }^{94}$ Powers, Andean Journeys, S. 7.

${ }^{95}$ Nicolás Sánchez-Albornoz, „Una dicotomía indígena. Originarios y forasteros en el alto Perú”: Ibero Americana Pragensia, 10 (1976), S. 87-100; Thierry Saignes, „Las etnias de Charcas frente al sistema colonial (siglo XVII). Ausentismo y fugas en el debate sobre la mano de obra indígena, 1595-1665”: Jahrbuch für Geschichte von Staat, Wirtschaft und Gesellschaft Lateinamerikas, 21 (1984), S. 27-75; Wightman, Indigenous Migration; Raquel Gil Montero / Axel E. Nielsen, „The 'Forasteros' of Lípez. 
außerdem gibt es einzelne Studien für Nordperu und die Audiencia de Quito. ${ }^{96}$ Die Verbindungen der forasteros zu ihren Ursprungsgemeinden variierten stark, teils zahlten sie dort weiterhin Tribut als originarios und leisteten sogar mita-Dienste, teils nicht; meist jedoch nur in der ersten Generation. Da die forasteros nach Verlassen ihrer Heimatgemeinde oft keinen Zugriff mehr auf Land hatten, ${ }^{97}$ mussten sie i.d.R. keine mita mehr leisten und zahlten keinen oder weniger Tribut als die sogenannten indios originarios. ${ }^{98}$ Wenn Sie als forasteros Tribut zahlten, war dieser direkt für den König bestimmt. In Cajamarca wurde dieser spezielle Tribut als quinto bezeichnet, und jene, die ihn bezahlten, als quinteros.

Es gab des Öfteren Streitigkeiten darüber, an welchem Ort die forasteros ihren Tribut zahlen sollten. ${ }^{99}$ Die schwankenden räumlichen Zugehörigkeiten der forasteros sollten Ende des 17. Jahrhunderts abgeschafft werden. Im Rahmen der Visitation des Duque de la Palata 1683 sollten fortan alle Indigenen an ihrem Wohn- und nicht in ihrem Herkunftsort registriert werden. Auslöser der Visitation war die sinkende Zahl von mitayos gewesen, was gleichwohl nicht an deren Tod, sondern an deren Migration und Konvertierung in forasteros und/oder yanaconas lag. Außerdem sollten forasteros und originarios gleichen Tribut- und mita-Verpflichtungen unterworfen sein. Dies wurde jedoch nicht umgesetzt; wohl auch aufgrund der unterschiedlichen Besitzverhältnisse. ${ }^{100}$

Ethnohistorical and Archaeological Perspectives on the Peoples of Bolivia's Southern Altiplano (Thirteenth to Eighteenth Centuries)": Colonial Latin American Review, 19: 3 (2010), S. 437-459.

${ }^{96}$ Powers, Andean Journeys; Albiez-Wieck, „Indian Migrants Negotiating”.

${ }^{97}$ Zumindest in Cajamarca gab es bereits im 17. Jahrhundert einige forasteros, die Land besaßen, sie stellten zu dieser Zeit jedoch eher die Ausnahme dar: ibidem.

${ }^{98}$ Laut Wightman, Indigenous Migration, S. 130, die zu Cuzco arbeitete, zahlten forasteros nur selten Tribut. Zumindest für jene, die in Minen arbeiteten, scheint dies Ende des 16. Jahrhunderts die Regel gewesen zu sein: „De los tributos”, Ley 14: Que los indios forasteros de la calidad, que se refiere, no tributen en las minas por aora. In der von mir untersuchten Dokumentation zu Cajamarca im 17. und 18. Jahrhundert zahlten sie immer Tribut.

${ }^{99}$ Z.B. Francisco de Ayala presentando Real Provisión para que se le rebajen el pago de tributos de 16 indios por hallarse estos ausentes de su registro de Huambos, $25 \mathrm{fs,}$ 12.02.1703-07.01.1704, ARC, Corregimiento, Protector de Naturales, Tributos, Leg. 01; hier geht es um die Zugehörigkeit in Huambos (nördliche Anden) oder in Orten rund um Piura (nördliche Küste). S. 40 .

${ }^{100}$ Wightman, Indigenous Migration, S. 31; Gil Montero, „Migración y tributación”, 
Die forasteros fügten sich in das lokale soziale System ein und bildeten, zumindest in einigen Regionen, eigene ayllus. ${ }^{101}$ Dies lag unter anderem daran, dass die Kategorie forastero erblich war, so dass auch die Nachkommen der eigentlichen Migranten als solche kategorisiert wurden, ohne dass sie immer selbst migrierten - weshalb ich teilweise von „Migranten“ in Anführungszeichen spreche. Sie lebten sowohl in den indigenen Gemeinden, als auch auf Haciendas. ${ }^{102}$ In diesem, aber auch in anderen Gesichtspunkten, ähnelten sie den yanaconas.

Im Gegensatz zu forastero war yanacona ein Begriff, der bereits unter den Inka existierte und von den Spaniern adaptiert wurde. ${ }^{103}$ Unter spanischer Herrschaft wurde zwischen yanaconas del rey und yanaconas de españoles unterschieden; erstere waren direkt dem König, letztere einzelnen Spaniern untertan. ${ }^{104}$ Theoretisch war auch ihr Status erblich, doch de facto kam es hin- und wieder vor, dass sie nur temporär als yanaconas tätig waren. Im Süden Perus wurde ein großer Teil der Indigenen, die Tribut und mita entkommen wollten, zu yanaconas und arbeiteten für Spanier. ${ }^{105}$ Auch yanacona mussten Tribut zahlen, jedoch augenscheinlich in geringerer Höhe als originarios. ${ }^{106}$ De facto scheinen

${ }^{101}$ Wightman, Indigenous Migration, S. 89 bezeichnet diese passenderweise als “kingroup of strangers”. Siehe auch: Albiez-Wieck, „Indian Migrants Negotiating”.

${ }^{102}$ Fälle, in denen forasteros auf haciendas lebten sind: El maestro de campo Damián de Cabrera, presentando la memoria de los indios tributarios y quinteros que sirven en varias haciendas de Guamachuco y Cajabamba y que estan debiendo a la Real Caja del tercio de San Juan y Navidad de 1727 a 1730, 27 fs y 70 recibos, 07.01.1731-31.01.1733, ARC, Corregimiento, Causas Ordinarias, Tributos, Leg. 03, Exp. 06; Memoria de los indios tributarios de las parcialidades de Cajamarca que están asignados en diversas haciendas del corregimiento de Cajamarca, Huamachuco y Huambos, 65 fs, 06.01.173402.07.1735, ARC, Corregimiento, Causas Ordinarias, Tributos, Leg. 03.

${ }^{103}$ Carlos Sempat Assadourian, El sistema de la economía colonial. El mercado interior, regiones y espacio económico, México, D.F.: Editorial Nueva Imagen, 1983, S. 315-318 weist auf die großen Unterschiede der spanischen im Vergleich zu den inkaischen yanacona hin.

${ }^{104}$ Gil Montero / Nielsen, „The ‘Forasteros””, S. 49-50.

105 Thierry Saignes, „Ayllus, mercado y coacción social. El reto de las migraciones internas en Charcas (siglo XVII)": Olivia Harris / Brooke Larson / Enrique Tandeter (Hg.), La Participación indígena en los mercados surandinos. Estrategias y reproducción social siglos XVI a XX, La Paz, Bolivia: Centro de Estudios de la Realidad Economica y Social, 1987, Bd. 111-158, S. 137; Francisco Cuena Boy, „Yanaconazgo y derecho romano. ¿Una conjunción extravagante”: Revista de Estudios Histórico-Jurídicos, 28 (2006), S.401-424, hier S. 406; Gil Montero / Nielsen, „The 'Forasteros””, 41,44,61; Wightman, Indigenous Migration, S. 151; Covey / Elson, „Ethnicity, Demography”, S. 326.

106 „De los tributos”, Ley 5: Que los yanaconas contribuyan como los demás indios, y sea para el rey; El capitan Domingo de Quevedo vecino de Cajamarca contra los bienes del capitan Estevan Moreno por deuda de 212 pesos y 4 reales provenientes del pago de tributos que debían los yanaconas de su Hacienda, 8 fs, 2 recibos, 23.04.1668-11.03.1670, 
sie in Südperu oft gar keinen Tribut gezahlt zu haben. ${ }^{107}$ Im Falle der yanaconas de españoles zahlten ihre Arbeitgeber für sie den Tribut; laut Covey und Elson ein wichtiger Grund für die Attraktivität dieser Kategorie. ${ }^{108}$

Bei der Kategorie der yanaconas del rey gab es große Überlappungen mit der der forasteros, sowohl im Süden Perus als auch in Cajamarca. Teilweise wurden die Begriffe synonym verwendet, teilweise wechselten Personen im Laufe ihres Lebens von der Kategorie der forasteros hin zu yanaconas und umgekehrt. ${ }^{109}$ Diese enge Verbindung lag wohl daran, dass der Tribut sowohl der forasteros als auch der yanaconas del rey direkt für den König bestimmt war.

Die Verwendung des Begriffs Migrant ist deutlich einleuchtender für die koloniale Kategorie des vago, vagabundo oder vagamundo, was man als Vagabund übersetzen könnte. Sowohl in Neuspanien als auch in Peru wurden mit diesen Begriffen nicht nur Indigene, sondern Personen anderer calidades ${ }^{110}$ bezeichnet, also auch Spanier, Mestizen und afrodescendientes. Der gemeinsame Nenner war dabei die Tatsache, dass sie keiner Gemeinde oder sozialen Einheit zugeordnet waren, und demnach auch keinen vecino-Status innehatten; auch hatten sie keinen festen Beruf oder Arbeitgeber. Seit dem 16. Jahrhundert wurden diese Vagabunden als schädlich für die Gesellschaft und als potentielle Störenfriede mit zweifelhafter Moral betrachtet. Es gab zahlreiche übergreifende königliche aber auch lokale Gesetze und Anordnungen,

ARC, Corregimiento, Causas ordinarias, Tributos, Leg. 02, siehe auch: Cuena Boy, „Yanaconazgo y derecho”, S. 407. Covey / Elson, „Ethnicity, Demography”, S. 325. weist für Südperu darauf hin, dass yanacona bereits in einem jüngeren Alter mit der Tributzahlung zu beginnen hatten, aber dass die Kategorie des yanacona dennoch attraktiver war als die der originarios. Siehe auch Gil Montero / Zagalsky, „Colonial Organization”, S. 75.

${ }^{107}$ Gil Montero, „Migración y tributación”, S. 55-56 berichtet für ihre Region, dass nur 3\% der yanacona tatsächlich Tributzahlungen entrichteten.

${ }^{108}$ Covey / Elson, „Ethnicity, Demography”, S. 311-312.

${ }^{109}$ Für Südperu, siehe Montero / Oliveto / Longhi, „Mano de obra”, S. 79; SánchezAlbornoz, „Una dicotomía indígena”, S. 53-54; Cuena Boy, „Yanaconazgo y derecho”; für Cajamarca siehe Albiez-Wieck, „Indian Migrants Negotiating”.

110 Grewe, Ethnizität, Staatsbürgerschaft und Zugehörigkeit, S. 275 definiert überzeugend: „Das Konzept der calidad hatte verschiedene Bedeutungsdimensionen wie Abstammung, Reputation, korporative Zugehörigkeit und Rechtsstatus und war damit ein Konzept sozialer Differenzierung, das nicht nur aus der religiösen Kategorie der limpieza de sangre erwuchs, sondern auch deutliche Parallelen zu Konzepten wie Ehre und Adel aufwies. (...) Die Kategorien der calidad wiesen zwar Dimensionen auf, die als ethnisch aufgefasst werden können, aber das Konzept ist in erster Linie im Zusammenhang mit den Strategien spanischer Herrschaftslegitimation, der korporativen Gesellschaftsordnung und religiösen Reinheitsvorstellungen zu betrachten.“

Jahrbuch für Geschichte Lateinamerikas | Anuario de Historia de América Latina 
die das Phänomen der Vagabunden zu beenden suchten. Es ist zu vermuten, dass die Hauptmotivation bei der Bekämpfung des Vagabundentums darin bestand, dass diese, zumindest im 16. und Teilen des 17. Jahrhundert keinen Tribut zahlten. In der Audiencia de Quito wurde laut Powers der Begriff vagamundo synonym mit dem Begriff des forastero verwendet, da beide von der mita befreit waren, aber einen reduzierten Tributsatz zu zahlen hatten. ${ }^{111}$ Im südlichen Andenraum war auch der Begriff mostrenco gebräuchlich. ${ }^{112}$ In Neuspanien wurde der Begriff vago auch als Tributkategorie relevant, wie weiter unten ausgeführt werden soll.

Im Gegensatz zu vago existierten die Katgorien indio forastero und yanacona in Neuspanien nicht. ${ }^{113}$ Am ehesten vergleichbar, insbesondere mit der Kategorie yanacona, ist der neuspanische Begriff des indio laborío. ${ }^{114} \mathrm{Im}$ 16. Jahrhundert entwickelte sich der Begriff laborío aus dem Begriff naborío, da diese in labores in Minen und in der Landwirtschaft arbeiteten. Zeitweise wurden beide Begriffe synonym verwendet. ${ }^{115}$ Einerseits war laborío eine Arbeitskategorie und bezeichnete Bedienstete und Arbeiter auf Haciendas und in Minen, die in Zentralmexiko auch als gañanes bekannt waren. Neben Indigenen arbeiteten auch afrodescendientes häufig auf Haciendas und in Textilund Zuckermühlen. ${ }^{116}$ Es ist interessant zu erwähnen, dass in Guatemala der Tribut der afrikanischstämmigen Bevölkerung als laborío-Tribut

\footnotetext{
111 Powers, Andean Journeys, S. 87.

112 Raquel Gil Montero, Los yanaconas en el siglo XVII, La Paz, Bolivia: 2017; Carlos Díaz Rementería, „En torno a un aspecto de la política reformista de Carlos III. Las matriculas de tributarios en los virreinatos de Perú y Río de la Plata”, 147-148 (1977), S. 51-139, hier S. 57-58.

${ }^{113}$ In Neuspanien taucht der Begriff forastero in der Bedeutung Fremder, Ausländer zwar gelegentlich in den Quellen auf; er bezeichnete aber keine klare Kategorie. Am ehesten ähnelt die Verwendung des Begriffes forastero in Neuspanien derjenigen aus Peru in einigen Abschnitten einer Ausgabe von 1881 von Fonseca und Urrutía: Fabián de Fonseca / Carlos de Urrutia, Historia general de Real Hacienda, México, 1881, S. 701 (párrafo 80) - 707 (párrafo 91). https://archive.org/stream/historiagenerald00fons\#page/ n5/mode/2up [14-03-17].

${ }^{114}$ Chantal Cramaussel, Poblar la frontera. La provincia de Santa Bárbara en Nueva Vizcaya durante los siglos XVI y XVII, Zamora, Michoacán: El Colegio de Michoacán, 2006, S. 234 hat die Ähnlichkeit zwischen yanaconas und laboríos erwähnt.

${ }^{115}$ Manchmal sogar in ein und demselben Textabschnitt, beispielsweise in: Para que se guarde y cumpla el mandamiento del señor virrey, Marques de Guadalcazar, aqui inserto, sobre los indios laborios que sirven en las haciendas de minas, no habiendo proveido cosa en contrario y se verifique con Pedro de Iriarite Navarro, 33 fs, 1632, AGNM, General de Parte, Vol. 7, Exp. 48.

${ }^{116}$ Indigenen war es verboten, in Textilmühlen, den obrajes, zu arbeiten: Sobre obrajes en la Nueva España, 21 fs, 29.10.1709, AGI, Lima 474, f. 3vs.
} 
bezeichnet wurde. ${ }^{117}$ Andererseits war laborío eine Tributkategorie, welche sich auf Indigene ohne Mitgliedschaft in indigenen Gemeinden bezog, weshalb diese keinen Zugriff auf die kommunalen Ländereien hatten. Als solche mussten sie einen geringeren Tribut zahlen als die indios de pueblo, wie die originarios in Neuspanien genannt wurden, und es gab Überlappungen mit der Kategorie der vagos. Ihr Tribut wurde wie bei den forasteros und yanaconas - in der Regel nicht von indigenen Kaziken, sondern von den spanischen Verwaltern der Haciendas eingetrieben. Dies war darin begründet, dass die Hacienda-Besitzer den Tribut für sie gesammelt zu entrichten hatten; gleiches galt für die dort arbeitende afrikanischstämmige Bevölkerung.

Wie die Dokumentation zum späten 16. und 17. Jahrhundert vermuten lässt, zahlten die laboríos oft gar keinen Tribut. Für einige Minenorte in Neuspanien gab es für sie offizielle Ausnahmen von der Tributpflicht, ${ }^{118}$ aber spätestens ab 1575 gab es verschiedene Gesetze, dass Arbeiter auf Haciendas und in Minen einen „moderaten“ Tribut zu zahlen hatten. ${ }^{119}$ In der Instrucción des Vizekönigs Gaspar de Zuñiga wurden neben den „naturales de los pueblos“, die „mulatos y negros libres“ sowie die „indios laboríos“ als Tributkategorien aufgezählt, die beide Tribut in der gleichen Höhe zu entrichten hatten und die in den Tributlisten separat aufgelistet werden sollten. ${ }^{120}$ Diese 1575 und erneut $1612^{121}$ angeordnete Erfassung und Eintreibung getrennt nach diesen drei Kategorien scheint allerdings im 17. Jahrhundert nicht stringent umgesetzt worden zu sein.

${ }^{117}$ Der König schrieb an den Generalkapitän der Audiencia de Guatemala: „que de los mulatos y mulatas negros y negras libres de todos mis reinos de las yndias se le cobra el tributo que llaman del laborio y que en esa ciudad y en el valle esta a cargo de los ofisiales de mi real hasienda la cobransa" Expediente sobre la forma de cobrar el tributo del laborio, 03.07.1683-04.05.1684, f. 3r, AGI, Guatemala, 28, R.2, N.38.

118 Beispielsweise "CLXV. Vuestra excelencia reserva de tributos y servicios personales a los indios naborios de las minas de Pachuca, como su majestad lo tiene mandado y lo ordenó generalmente el virrey conde de Coruña”: Silvio Zavala / María Castelo (Hg.), Fuentes para la historia del trabajo en Nueva España, México: Fondo de Cultura Económica, 1939-1946, Bd. V - 1602-1604, S. 160-161; für Haciendas und Minen in Nueva Galicia: AGI Expediente sobre la forma.

119 Das Gesetz von 1575 wurde 1593 erneuert: „De los tributos”, Ley 9: Que los indios, que trabajaren en minas, huertas, y otras haciendas, tributen; ibidem, Ley 10: Que los indios ocupados en estancias, obrajes, y otros exercicios, tributen para el rey; 1598 folgte diese vizekönigliche Anordnung: AGNM Instrucciones hechas por. Allerdings wurde die Tributpflicht für laboríos in den Minen im 18. Jahrhundert erneut bekräftigt, was darauf schließen lässt, dass diese bislang nicht immer Tribut gezahlt hatten: Gutiérrez Núñez, „La Real Hacienda”, S. 37-39.

120 AGNM Instrucciones hechas.

121 „Real Provision acordada”, Que se forme Padron separado de los Indios Laborios, S. 17

Jahrbuch für Geschichte Lateinamerikas | Anuario de Historia de América Latina 
Ich habe nur wenige Dokumente gefunden, die sich mit der Tributeintreibung von Indigenen außerhalb der pueblos de indios im 17. Jahrhundert befassen. Meist beziehen sich diese auf die Schwierigkeiten bei der Tributeintreibung von Indigenen, die als extravagantes oder vagamundos und Bedienstete von Spaniern bezeichnet wurden, auch aufgrund der mangelnden Kooperation der spanischen Arbeitgeber. ${ }^{122}$ Die Tributhöhe der vagabundos entsprach in etwa dem, was ein halber Tributzahler zu zahlen hatte; laboríos hingegen mussten wohl schon ab 14 Jahren zahlen.

\section{Die bourbonischen Reformen im 18. Jahrhundert}

Im Verlauf des 18. Jahrhunderts implementierte die spanische Krone, die nun nicht mehr in Händen der Habsburger, sondern der Bourbonen war, umfangreiche Reformen. Diese sogenannten bourbonischen Reformen sollten Spanien und seinen Kolonien eine bessere Position im Wettkampf mit den imperialen Mächten Großbritannien und Frankreich ermöglichen. ${ }^{123}$ Die Hochphase fand in der Regierungszeit Karls III (1759-1788) statt. Verschiedene Visitationen, insbesondere unter José de Gálvez und José Antonio de Areche, waren für die Vorbereitung und Durchführung der Reformen zentral. ${ }^{124}$ Eines der Ziele der Reformen

\footnotetext{
122 El Gobernador, los Alcaldes y los principales de la ciudad de Valladolid, solicitan ante la autoridad (no se especifica ante quien, ni cargo) "que el tributo que se resta para cumplir los muertos y huidos, se saque y cubra de la caja de comunidad" por no poder hacerlo ellos y estar sufriendo vejaciones de prisión, 4 fs, 1614, AHMM, Hacienda, Caja 1, Exp. 3-A; Francisco Perez de Santa Maria, Gobernador y demás Alcaldes, Regidores y Oficiales de Republica de Valladolid, ante el Alcalde Ordinario Francisco Peraza Ynfante, solicitan se les despache mandamiento para cobrar el tributo a los indios e indias que dan servicio personal a los españoles, a los vagamundos y realengos para que puedan cubrir lo correspondiente a los tributos, imposibilitados por los muertos que han tenido en el padrón, 3 fs, 1637, AHMM, Hacienda, Caja 1, Exp. 4-C; AHMM Mandamiento del virrey; El comisionado de la real hacineda solicita a Onesimo Antonio Duran intendente corregidor para que le señale si debe o no matricular a los vagos o arrimados que laboran en las haciendas a razón de la peticion de los deudores de no pagar tributos este tipo de gente, 6 fs, 1798, AHMM, Hacienda, Caja 6, Exp. 17. Eine ähnliche Aussage trifft Marichal, „Money, Taxes, and Finance”, S. 434-435.

${ }^{123}$ Pollack, „Hacia una historia”, S. 99.

124 Martha Terán, „Documentos selectos de la tributación tardía. Marco de la tributación borbónica de la Nueva España”: Martha Terán (Hg.), Tributos tardíos de la Nueva España. Programa interactivo, México, D.F.: 2016, Bd. I, S. III-IV; John Robert Fisher, El Perú borbónico, 1750-1824, Lima: IEP Instituto de Estudios Peruanos, 2000, Bd. 28, S. 31-33; Gutiérrez Núñez, „La Real Hacienda”; Horst Pietschmann, „Conciencia de identidad, legislación y derecho. Algunas notas en torno al surgimiento
} 
war eine Steigerung der Tributeinnahmen auch durch eine effizientere Verwaltung. Dieses Ziel war durchaus erfolgreich. In Peru wurde der Tribut in der zweiten Hälfte des 18. Jahrhunderts die größte Einnahmequelle der Krone und die Einnahmen hatten sich von den 1680ern bis zu den 1780ern fast verzehnfacht. In der Audiencia de Charcas überstiegen die Einnahmen aus dem Tribut erstmals in den 1780ern die aus dem Bergbau. In Neuspanien ist ein stetiger Anstieg der Tributeinnahmen über die Kolonialzeit hinweg zu verzeichnen, der sich durch die Maßnahmen von Gálvez intensivierte. ${ }^{125}$

Allgemeingültige Zahlen für die Tributhöhe sind auch für diese Zeit aufgrund der starken regionalen Schwankungen schwierig. Als annähernder Richtwert sind für die indigene Bevölkerung in Neuspanien die in der Ordenanza de Intendentes 1786 festgelegten 16 reales ergänzt um einen real de ministros y hospitales zu nennen. ${ }^{126}$ Für den Süden Perus gibt Serulnikov den Betrag von neun pesos an. ${ }^{127}$ Die nachdrücklichere Einforderung von Tributpflichten zeigt sich in Cajamarca und Michoacán in einem Anstieg der Eingaben an die Obrigkeit mit dem Ziel, in eine attraktivere Tributkategorie zu wechseln oder gar als „exento“, als befreit von der Tributpflicht, anerkannt zu werden und somit die Reformbemühungen zu unterlaufen.

Die bourbonischen Reformen sind von einigen Autoren als Umformulierung des „kolonialen Paktes“ interpretiert worden, da sie ein neues hegemonisches Modell verkörperten. ${ }^{128}$ Auch die Bezeichnung

del ‘individuo' y de la 'nación' en el discurso político de la monarquía española durante el siglo XVIII”: Sybille Große (Hg.), Dulce et decorum est philologiam colere. Festschrift für Dietrich Briesemeister zu seinem 65. Geburtstag, Berlin: Domus Ed. Europaea, 1999, Bd. 1, S. 535-554; Rafael Diego-Fernández Sotelo / María Pilar Gutiérrez Lorenzo / Arrioja Díaz Viruell, Luis Alberto (Hg.), De reinos y subdelegaciones. Nuevos escenarios para un nuevo orden en la América borbónica, Zamora, Michoacán: El Colegio de Michoacán; Universidad de Guadalajara; El Colegio Mexiquense, 2014; García Ayluardo, Las reformas borbónicas; Stavig, „The world of Tupac Amaru”.

${ }^{125}$ Klein, The American Finances, S. 20-22, S. 108; Gil Montero, „Population and Economy”, S. 200-201; Gutiérrez Núñez, „La Real Hacienda”, S. 76.

126 „Real Ordenanza”, Art. 137.

127 Sergio Serulnikov, Subverting Colonial Authority. Challenges to Spanish Rule in Eighteenth-century Southern Andes, Durham: Duke University Press, 2003, S. 231.

${ }_{128}$ Serulnikov, „Customs and Rules”, S. 246-248; Guardino, The Time of Liberty, S. 91-93; Sánchez Silva, Indios, comerciantes y burocracia, S. 137-138; S. 205-206 beschäftigt sich für Oaxaca ausführlich mit den ,neuen Regeln”, die den Indigenen durch die Liberalen im 19. Jahrhundert auferlegt wurden. Diese umfassten unter anderem die Aufteilung ihres Gemeindelandes und die Einführung neuer Steuern. Die Indigenen empfanden dies seiner Ansicht nach als Zerbrechen des Gleichgewichts in den Gemeinden. Allerdings fand der Großteil dieser für den kolonialen Pakt zentralen Änderungen erst nach der Unabhängigkeit statt. Tristan Platt, Estado boliviano y ayllu 
„Neueroberung Amerikas“ wird verwendet. ${ }^{129}$ Die Reformen führten zu einer verstärkten Kontrolle und Belastung der Bevölkerung, zu einer Neuordnung der Beziehungen zwischen Herrschern und Beherrschten und damit, laut Castro Gutiérrez, zu einem „neuen Autoritarismus“. ${ }^{130}$

Wichtige Modifikationen in der Tributeintreibung begannen 1769 in Neuspanien, 1779 in der Audiencia de Quito und 1778 in den Vizekönigreichen Perú und Río de la Plata; zentral war die Ordenanza de Intendentes von 1786. Es ging nicht nur um neue Gesetze und Verordnungen, sondern auch um die Durchsetzung bereits bestehender. ${ }^{131}$ Laut Pollack waren folgende Regelungen zentral: Die Umsetzung einer regelmäßigen Erneuerung der matrículas alle fünf Jahre, die Stärkung eines Kautionssystems, mit dem Dritte die Abgabe der Tribute durch die alcaldes mayores, corregidores und später die subdelegados sicherten, die Reduzierung von Ausnahmen von der Tributpflicht und die Zentralisierung der Verantwortlichkeiten für die Eintreibung. ${ }^{132}$ Die Tributpflicht für mulattische Frauen wurde 1786 „im ganzen Reich“ abgeschafft. ${ }^{133}$ Die Tatsache, dass die Tributpflicht für indigene alleinstehende Frauen 1758 und 1765 erneut aufgehoben wurde, lässt vermuten, dass diese Frauen zwischenzeitlich zumindest teilweise gezahlt hatten; ${ }^{134}$ eine Praxis, die ich aus meiner Quellenkenntnis zu

andino. Tierra y tributo en el norte de Potosí, Lima: Inst. de Estudios Peruanos, 1982, Bd. 9, S. 20 spricht für Bolivien gar von einer Art Fortführung dieses kolonialen Paktes in den ersten Dekaden nach der Unabhängigkeit. Er nennt ihn "Reziprozitäts-Pakt”. Die Essenz dieses Paktes habe in der Anerkennung der Landnutzungsrechte der ayllus im Gegenzug für die Leistung der traditionellen Zahlungen und Arbeitsdienste gelegen.

129 Klein, The American Finances, S. 108 sieht die mit dieser Bezeichnung verbundene Interpretation zumindest teilweise kritisch. Er schreibt: „While the evidence from the tax records would seem to imply that long-term reform did not lead to fiscal oppression and consequent economic decline, the second theme of a rapine policy after 1790, at least for Mexico, is still an open question."

${ }^{130}$ Felipe Castro Gutiérrez, Nueva ley y nuevo rey. Reformas borbónicas y rebelión popular en Nueva España, Zamora Michoacán: Colegio de Michoacán, 1996, Kapitel 1, 3, 6 .

${ }^{131}$ Real Díaz, Estudio diplomático, S. 223 definiert ordenanza als „suma de órdenes concretas - muchas de ellas ya publicadas y en vigor - que en un momento preciso se reúnen, de una manera conjunta”.

132 Pollack, „Hacia una historia”, S. 99-100; Real ordenanza para el establecimiento e instruccion de intendentes de exército y provincia en el reino de la Nueva-España. De orden de Su Magestad, Madrid, 1786. https://archive.org/stream/ realordenanzapar01nvguat\#page/164/mode/2up [27-10-16].

${ }^{133}$ Fonseca / Urrutia, Historia general, S. 434-435 (párrafo 58). Mulattische Frauen, die mit Sklaven verheiratet waren, mussten jedoch scheinbar laut einem Beschluss (auto) von 1763 weiterhin zahlen: ibidem, S. 439 (párrafo 68).

${ }^{134}$ Ibidem, S. 434-435 (párrafo 58), 440 (párrafo 70); „Real Provision acordada”, Que las Viudas, Doncellas, y Solteras estàn excemptas del Tributo. Real Cedula de 4. de 
Cajamarca und Michoacán jedoch nicht bestätigen kann. Die Zahlung des Tributs in Form von Sachleistungen scheint durch die bourbonischen Reformen immer weiter zurückgedrängt worden zu sein und gegen Ende des 18. Jahrhunderts war die Zahlung in Geld allgemein verbreitet. ${ }^{135}$

Im Folgenden sollen nun die Besonderheiten für die beiden Vizekönigreiche mit ihren jeweiligen Tributkategorien nachgezeichnet werden. Dabei sollen die Bezüge zwischen den verschiedenen Kategorien innerhalb der Regionen im Zentrum stehen, da die Veränderung der Abgrenzungen und Gemeinsamkeiten zwischen den Kategorien teilweise Ziel der Reformen war.

\section{Peru}

In Peru begannen die Bestrebungen der Veränderungen bezüglich der Kategorien der forasteros, yanaconas und indios originarios bereits in der ersten Hälfte des 18. Jahrhunderts. Der Vizekönig José de Armendáriz, Marqués de Castelfuerte, ließ von 1725 bis 1740 eine umfassende Visitation durchführen. Die Maßnahmen, die dieselbe begleiteten, beinhalteten eine Umverteilung brachliegender Ländereien an jene forasteros, die kein Land besaßen. In der Folge sollten dann alle landbesitzenden forasteros an ihrem Wohnort (und nicht am Ursprungsort) Tribut in voller Höhe zahlen und mita-Dienste leisten, genau wie originarios. Diese Maßnahme sollte auch alle yanaconas, die

Noviembre de 1758. Auch in der „Instruccion á que se han de arreglar los Comisionados Jueces de Matrículas de Tributarios en las que formen en las Provincias de Nueva España, 2 de diciembre de 1793. AGN, Tributos, Vol. 60, Exp. 9, fs. 209-223”: Martha Terán (Hg.), Tributos tardíos de la Nueva España. Programa interactivo, México, D.F., 2016, Art 29: Que las mugeres están exêntas del Tributo.wird darauf hingewiesen, dass Frauen von der Tributzahlung befreit waren.

${ }^{135}$ Hierzu gab es im Laufe des 18. Jahrhunderts verschiedene Erlässe: Nuevo orden en la tributación de los indios, f.139vs-142vs, 05.03.1724, AGI, Guadalajara 233, L.11.; „Reglamento y Ordenanzas que, con las Adiciones que se expresan, manda su Majestad observar para el gobierno y administracion del Ramo de Reales Tributos en las Provincias del Vireynato de Nueva España. Año de 1770. Reimpresas de órden del Señor Superintendente Subdelegado de Real Hacienda, don Fernando Joseph Mangino, en México, año de 1787, en la imprenta de D. Felipe de Zúñiga y Ontiveros. AGN, Tributos, Vol. 23, Exp. 14, fs. 356-388”: Martha Terán (Hg.), Tributos tardíos de la Nueva España. Programa interactivo, México, D.F., 2016. Que los Ratéos se formen sin quebrados, y se omitan las expresiones de conmutacion de Ropa, Cacao etc.; Fonseca / Urrutia, Historia general, S. 428-429 (párrafo 43-45), schreiben im Jahr 1791, dass zu ihrer Zeit die Zahlung in Form von Geld in Neuspanien allgemein üblich war. 
nicht einer encomienda zugeordnet waren, umfassen. ${ }^{136}$ Die logische Folge dieser Maßnahmen wäre also eine Rekategorisierung der forasteros und yanaconas in originarios gewesen, d.h. das Verschwinden „migrantischer“ Kategorien.

De facto gab es aber keine umfassende Umsetzung der Anordnungen. Statt $\mathrm{zu}$ verschwinden wurde die forastero-Kategorie in der Folge aufgeteilt in jene mit und jene ohne Land: forasteros con tierras und forasteros sin tierras. ${ }^{137}$ Erstere hatten ähnliche Verpflichtungen wie die originarios, letztere, zumindest in Cajamarca, hatten nach wie vor lediglich eine reduzierte Tributsumme zu zahlen. ${ }^{138}$ Ende des 18. und zu Beginn des 19. Jahrhunderts tauchen sowohl forasteros als auch yanacona in den von mir untersuchten Quellen aus Cajamarca vorrangig als Arbeiter auf Haciendas auf. Dort arbeiteten sie teilweise ähnlich wie Schuldknechte und flohen bisweilen aufgrund der harten Arbeitsbedingungen. Ähnliches gilt für afrodescendientes, die in Cajamarca teilweise als mixtos bezeichnet wurden. ${ }^{139}$

Für alle tributpflichtigen Gruppen bedeutsam war die Visitation von José Antonio de Areche im Jahr 1777. Er hatte unter Gálvez in Mexiko gedient. In Peru vereinheitlichte er die Tribut- und Steuereintreibung und modernisierte die zugehörige Bürokratie, was zu einer deutlichen

136 Adrien J. Pearce, „The Peruvian Population Census of 1725-1740”: Latin American Research Review, 36: 3 (2001), S. 69-104.

${ }^{137}$ In der Audiencia de Quito gab es im 18. Jahrhundert eine andere terminologische Unterscheidung, auf die Andrien hinweist. Die „migrantische“ Bevölkerung wurde unterschieden in forasteros und coronas. Erstere hatten nach wie vor Verbindungen zu ihrem Heimatort, bei Letzteren war dieser nicht bekannt. Kenneth J. Andrien, The Kingdom of Quito, 1690 - 1830. The State and Regional Development, Cambridge: Cambridge University Press, 1995, Bd. 80, S. 42, 232.

${ }^{138}$ Für eine ausführlichere Diskussion am Fallbeispiel Cajamarca siehe Albiez-Wieck, „Indian Migrants Negotiating”. Dort wird auch darauf hingewiesen, dass einzelne forasteros auch vor dieser Maßnahme bereits Land besaßen. Laut Serulnikov, Subverting Colonial Authority, S. 231, der zum Süden Perus arbeitet, bezahlten sie fünf bzw. sieben pesos Tribut.

${ }^{139}$ Siehe z.B. Santos Romero, mixto quintero del pueblo de Jesús, solicitando que no se lo considere en la matrícula de tributarios de la Hda Galic por ser indio libre, 6 fs, 02.07.-30.07.1817, ARC, Intendencia, Tributos, Leg. 01; El protector general de naturales Josep Antonio de Arce, en nombre de Fabian Clemente, indio tributario de la Hacienda de Polloc, contra Don Domingo de Quevedo, por ser obligado a trabajar como yanacona y haber encarcelado a su esposa en dicha hacienda, 9 fs, 13.01.-16.02.1776, ARC, Corregimiento, Protector de Naturales, Tributos, Leg 02, D. Juan Antonio López Valera, presbítero de la villa de Cajamarca, dueño de la hacienda Jancat, denunciando a los yanaconas José Benito Pichos y Felipe Vargas, por daños y perjuicios, ocasionados al haber fugado de la hacienda, 4 fs, 04.11.1779, ARC, Corregimiento, Causas ordinarias, Leg. 149; Exoneración de mita en Chota, Cajamarca, 109 fs, 23.09.1771, AGNP, Superior Gobierno, Serie Hacienda (GO-BI 2), Leg. 69, Cuad. 170.

Jahrbuch für Geschichte Lateinamerikas | Anuario de Historia de América Latina 
Erhöhung der Tribut- und Steuereinnahmen führte, etwa durch die Ausweitung der alcabala-Pflicht. ${ }^{140}$ Eine weitere Abgabe, die Areche 1779 versuchte einzuführen, war die contribución militar zur Bezahlung von Offizieren, die die Provinzmilizen trainierten. Diese contribución sollte auch von allen freien afrodescendientes gezahlt werden, woraufhin es in Lambayeque in Nordperu einen Aufstand gab, an dem die dauerhafte Einführung scheiterte. ${ }^{141}$ Laut Campbell hatte der Rechnungshof 1777 entschieden, dass lediglich Indigene und zambos, d.h. Nachkommen aus Ehen zwischen Indigenen und afrodescendientes, Tribut zahlen sollten. Areche hatte die Befugnis, die Tributpflicht lediglich auf die casta-Gruppe der cholos auszuweiten, allerdings fügte er eigenmächtig auch noch pardos und Mestizen hinzu. ${ }^{142}$ Diese Anordnung scheiterte jedoch. ${ }^{143}$ So waren bis zur Unabhängigkeit laut Mansilla Escobedo zambos oder zambaigos sowie cholos die einzigen Kategorien der afrikanischstämmigen Bevölkerung, die in Peru Tribut zu zahlen hatten; eine Gepflogenheit, die vom visitador Jorge de Escobedo, dem Nachfolger Areches, bestätigt wurde. ${ }^{144}$ Die Tatsache, dass ausgerechnet diese Kategorien der afrodescendientes Tribut zahlten, lag vermutlich darin begründet, dass die derart kategorisierten Personen teilweise von Indigenen abstammten. In Cajamarca gibt es vereinzelte Hinweise aus dem 18. Jahrhundert, dass Mulatten keinen Tribut zahlten und Personen in diese hierdurch attraktivere Kategorie wechseln wollten. ${ }^{145}$

\footnotetext{
${ }^{140}$ Leon G. Campbell, „Black Power in Colonial Peru. The 1779 Tax Rebellion of Lambayeque”: Phylon, 33: 2 (1972), S. 143.

${ }^{141}$ Campbell, „Black Power”.

142 Ibidem, S. 143-145.

143 John Fisher, Bourbon Peru, 1750-1824, Liverpool: Liverpool University Press, 2003, S. 56.

${ }^{144}$ Mansilla Escobedo, „El tributo de los zambaigos”, S. 52-54. Ramos Gómez / Ruigómez Gómez, „Una propuesta a la corona”, S. 102-110 weisen darauf hin, dass in der Audiencia de Quito der oidor Pedro Martínez de Arizala bereits in den 1830er Jahren den Vorschlag machte, dass Mestizen und afrodescendientes den gleichen Tribut wie Indigene zahlen sollten. Dieser Vorschlag wurde jedoch nicht umgesetzt und 1748 definitiv abgelehnt. Die Kategorie cholo wird von Campbell, „Black Power“, S. 143 nicht als afrikanischstämmig definiert, sondern als ,vague classification designed to distinguish between peasants of mostly Indian blood on the one hand and mestizo farmers and artisans on the other."

145 Z.B. Antonio Pimentel, solicitando comprobación de su partida de nacimiento, donde declara que es hijo de padres de mulatos, por lo que no debe pagar el quinto real por ser mulato libre, 4 fs, 11.-14.09.1768, ARC, Corregimiento, Causas ordinarias, Leg. 142, ficha 3274.
} 


\section{Neuspanien}

Auch in Neuspanien war ein wichtiges Ziel der bourbonischen Reformen die Erhöhung der Einnahmen im Tributsektor, die über eine Vereinheitlichung der Abläufe und umfassendere Durchsetzung bestehender Regeln erfolgen sollte. Dies führte zu der klareren Herausbildung folgender Tributgruppen: indios de pueblo, indios laboríos und negros y mulatos libres, wobei die beiden letzteren in der Regel unter dem Begriff vagos zusammengefasst wurden.

In seinem Bericht von 1765 wies der Visitador Gálvez auf drei Problematiken hin, die die Einnahmen im Bereich der Tribute drückten: Unklarheiten bei der Registrierung und Abrechnung, Verspätungen bei der Eintreibung, d.h. nicht pünktlich zu den vorgesehenen tercios, und Zurückhaltung der königlichen Einnahmen durch die alcaldes mayores. Um die Einnahmen zu steigern schlug er vor, neue Registrierungen, d.h. matrículas vorzunehmen und die tasas zu vereinheitlichen, die Tributpflicht der afrikanischstämmigen Bevölkerung zu verallgemeinern, und ganz allgemein Ausnahmen und Privilegien sowie die Korruption einzuschränken. ${ }^{146}$ Die Erstellung neuer, umfassender matrículas hatte die bessere Kontrolle der tributpflichtigen Bevölkerung zum Ziel und sollte die vorher teils ungeregelte Erstellung normieren und eine Erstellung von retasas alle fünf Jahre sicherstellen. ${ }^{147}$ Dies führte in der Umsetzung teilweise zu Konflikten, unter anderem weil die Ersteller der neuen Listen angeblich viele vagos fälschlicherweise als indios de pueblo registriert hatten. Das grundsätzliche Recht auf Bewegungsfreiheit wurde zwar eingehalten, aber immer stärker eingeschränkt. ${ }^{148}$

Die stärkere Kontrolle der Tributpflicht der vagos war bereits vor Gálvez ein Ziel der Tributbeamten gewesen. Allerdings scheiterte dies oft schon an der ordnungsgemäßen Registrierung derselben. Die separate Auflistung von indios de pueblo und vagos, diese wiederum aufgeteilt in laboríos und mulatos war bis zur Mitte des 18. Jahrhunderts scheinbar kaum umgesetzt worden. Dies belegt insbesondere ein Brief des contador de tributos, Don Pedro Toral Valdes, aus dem Jahr 1762. Darin berichtet

\footnotetext{
146 Gutiérrez Núñez, „La Real Hacienda”, S. 36-37.

${ }^{147}$ Reyes García (Hg.), Catálogo del Ramo Tributo, S. VI-VIII.

148 Zavala, „La libertad de movimiento”, S. 243.; „Real Provision acordada”, Que se solicite con eficacia la restitucion de los ausentes; Felipe Castro Gutiérrez, „Migración indígena y cambio cultural en Michoacán colonial, siglos XVII y XVIII”: Colonial Latin American Historical Review, 7: 4 (1998), S. 438-439; Sobre restitución de indios a sus pueblos, 18 fs, 1752, AHCP, Caja 39D, Carp. 1.
} 
er, dass er sich alle bisherigen Tributlisten angesehen habe, und dass dort mulatos und laboríos nie separat aufgelistet wurden. Er regte an, diese schlechte Praxis, über die „fast zwei Jahrhunderte lang [...] nicht nachgedacht wurde,“ ${ }^{149}$ umgehend abzuschaffen und ab sofort laboríos und mulatos separat von den indios de pueblo aufzunehmen. Diese separate Aufführung, ohne Zuordnung zu einer indigenen Gemeinde, wurde in der Folge auch in verschiedenen ordenanzas angeordnet. ${ }^{150}$ Diese wurden dann auch tatsächlich in die Praxis umgesetzt, wie man in zahlreichen Tributlisten vom Ende des 18. und Beginn des 19. Jahrhunderts sehen kann, in denen die Tribute der laboríos und mulatos oft gemeinsam unter dem Oberbegriff vagos zusammengefasst wurden. ${ }^{151}$ Die Kategorisierung als vago hatte nicht unbedingt ein Leben lang Bestand, und Personen wurden manchmal nur während eines bestimmten Zeitabschnittes als vagos registriert. ${ }^{152}$

In vielen Dokumenten des 18. Jahrhunderts aus dem Bereich Tribut wird auf die Schwierigkeiten hingewiesen, den vago-Tribut sowohl in Minen als auch auf Haciendas einzutreiben. Dies lag unter anderem daran, dass die Hacendados ihre Bediensteten, Indigene und Mulatten gleichermaßen, nicht angaben. Auch in Städten tauchten die vagos oft nicht in den Tributlisten auf. ${ }^{153}$ Um alle Tributzahler zu erfassen, wurde

\footnotetext{
149 Propuesta hecha por el contador, f. 2vs.

150 „Reglamento y Ordenanzas”, 26, XXIX: Que haya un Libro de marca mayor para asentar las Tasaciones de Indios de los Pueblos de la Corona, su número y el de los Laboríos, y tambien los Negros y Mulatos libres conforme se expresa; Ordenanza para la formación de los autos de visitas y padrones y tasa de Tributarios de la Nueva España. Conde de Revillagigedo, 14 fs, 1793, 9, Foto 13 - f.11, foto 15, AGNM, Indiferente Virreinal, Caja 2923, Exp. 47; „Instruccion á que se han de arreglar”, Art. 19: Que se formen Padrones separados de los Tributarios que se expresan; „Artículos 124-141”, 138: Vagos, y otros dispersos de clase tributaria: cómo se ha de procurar que contribuyan la respectiva quota.

${ }^{151}$ Für eine Übersicht dieser Tributlisten, den estados generales de tributos, für ganz Neuspanien aus den Jahren 1805 und 1810: Terán, Tributos tardíos. Für etwas frühere Tributlisten, siehe Relación del número de tributarios matriculados de la provincia de México, Veracruz, Puebla, Oaxaca, Valladolid, intendencia de Guanajuato, Guadalajara, Zacatecas, Arispe, Mérida de los años 1792 a 1801, en la que se expresaron partidos, fechas de matricula, clases de tributarios y totales, en México, 13 fs, 1792-1801, AGNM, Indiferente Virreinal, Caja 4083, Exp. 07.

152 Ein Beispiel hierfür ist der Fall einiger Personen aus Aranza, Michoacán: Manuel Equigua, Nicolas Balencio y Antonio Rodriguez vecinos del pueblo de San Geronimo Aranza, ante el intendente corregidor de esta provincia Juan Antonio de Riaño, hacen la peticion de que se les baxe del nuevo padron de tributos ya que ellos son caciques estimados y respetados del pueblo de Aranza, 4 fs, 1788, AHMM, Hacienda, Caja 5, Exp.

153 Branciforte, Miguel de la Grúa y Talamanca, Marqués de, „Oficios al Subdelegado de Tulancingo ordenando que envíe información de qué indios y mulatos hay en este
} 22. 
die Regel erlassen, dass die koloniale Verwaltung informiert werden sollte, wenn Arbeiter sich zwischen Dörfern, Städten und Haciendas bewegten. Außerdem wurden die Hacendados wiederholt zur Zahlung des Tributs ihrer Angestellten aufgefordert. ${ }^{154}$

Fernando Granados und Tutino haben für den Bajío, González Flores für Taximaroa, Michoacán, darauf hingewiesen, dass es nach der Migration auf eine Hacienda oft zum Wechsel von Tributkategorien von indio hin zu Spaniern oder Mulatten kam; Fernando Granados spricht außerdem von einer De-Ethnisierung innerhalb der Kategorie der indios laboríos. ${ }^{155}$ Daran scheint auch die von Gálvez wiedereingeführte Regel nichts geändert zu haben, dass Indigene sich anders zu kleiden hatten als die castas. ${ }^{156}$ In eine ähnliche Richtung weisen die Aussagen von Cramaussel und Becerra, laut denen die laboríos keinerlei Beziehungen zu ihren Ursprungsgemeinden unterhielten. ${ }^{157}$ Die komplette Lösung

Partido bajo la denominación de vagos, y también de los que están radicados y avecindados de mucho tiempo a esta parte en Pueblos, Ranchos o Haciendas con hijos y familia, y su opinión a si convendrá, o no, a los Subdelgados recibir por relación jurada los Tributos de Negros y Mulatos. Repetición de la Orden de Virrey al no recibir contestación del Subdelegado", University of Texas at San Antonio, 1796, http://digital.utsa.edu/cdm/ref/collection/p15125coll6/id/6606 [24-10-2016]; AHMM El comisionado; Representación del subdelegado de Angamacutiro, sobre las excusas que presenta el alférez de milicias Don Nicolás Arrambide, en dar noticia de sus sirvientes tributarios, fs 412-420, 15.03.1793, Tributos, Vol. 48, Exp. 9; „Matrículas de 1788”.

${ }^{154}$ Pedimiento del señor fiscal de real hacienda, sobre que se generalice lo resuelto para la provincia de Valladolid, relativo al modo de cobrar el tributo de los que trabajan en haciendas, ranchos, trapiches, etc, fs. 32-53, 07.05.1793-16.03.1798, AGNM, Tributos, Vol. 51, Exp. 2; AHMM Representación del subdelegado; „Real Provision acordada”, Que los Gobernadores, Oficiales de Republica, y dueños de Haciendas pongan de manifiesto â los Indios, y Sirvientes; „Reglamento y Ordenanzas”, 73: Que sea del cargo de los Hacenderos asegurar y pagar el Tributo de sus Gañanes und 74: Que en los propios términos paguen tambien los Hacenderos los Tributos de Indios Terrasgueros ó Arrendatarios und Que los mismos Hacenderos aseguren el Tributo de los Indios de jornal: varias advertencies con que deben admitirlos; y otras relativas á los Alcaldes Mayores; El subdelegado de Huétamo sobre recaudación de tributos de vagos, 2 fs, 1796, AHCP, Caja 60C, Exp. 6.

${ }^{155}$ John Tutino, „Soberanía quebrada, insurgencias populares, y la independencia de México. La guerra de independencias, 1808-1821”: Historia Mexicana, 59: 1 (2009), S. 11-75; Luis Fernando Granados, En el espejo haitiano. Los indios del Bajío y el colapso del orden colonial en América Latina, México, D.F.: Ediciones Era, 2016, S. 185-188.; José Gustavo González Flores, Mestizaje de papel. Dinámica demográfica y familias de calidad múltiple en Taximaroa (1667-1826), Zamora, Michoacán: El Colegio de Michoacán; Universidad Autónoma de Coahuila -Escuela de Ciencias Sociales, 2016, S. 230-231.

${ }^{156}$ Castro Gutiérrez, „Los indios”, S. 36.

${ }^{157}$ Cramaussel, Poblar la frontera, S. 237, 243; Celina G. Becerra Jiménez, Indios, españoles y africanos en los altos de Jalisco. Jalostotitlán, 1650-1780, Guadalajara: CUCSH; Culagos Ediciones, 2015, S. 49-50. 
von den indigenen Gemeinden traf für den Teil der permanent migrierten laboríos und ihre Nachkommen sicherlich zu, jedoch nicht für die temporär und zirkulär migrierenden Arbeiter. ${ }^{158}$

Die Tatsache, dass die laboríos weiterhin eine niedrigere Tributrate zahlen mussten, war offensichtlich eine starke Motivation für die indios de pueblo, ihre Dörfer zu verlassen. Zumindest beurteilte der Intendant von Valladolid dies in einem Brief aus dem Jahre 1800 so. Er forderte darin, dass die Tributhöhe der laboríos jener der indios de pueblo angepasst werden sollte, um die Entvölkerung der pueblos de indios zu verhindern. Allerdings scheiterte er mit seinem Ansinnen, ${ }^{159}$ was in der Folge auch wieder mit dem mangelnden Landbesitz der laboríos begründet wurde. ${ }^{160}$

Ein gescheitertes Ziel der bourbonischen Reformen war die Abschaffung der medios tributarios. Dies hätte bei einem Gelingen impliziert, dass alle Tributzahler die gleiche Summe gezahlt hätten. Dies wurde durch die Real Ordenanza de Intendentes angeordnet, die lediglich Frauen, Kaziken und ihre Erstgeborenen, sowie die Tlaxcalteken von der Zahlung des einheitlichen Tributes ausnahm. Die Umsetzung scheiterte auch daran, dass ledige Männer noch nicht vollwertige Mitglieder der Gemeinde waren und damit oft keinen Zugriff auf eigenes Land hatten. ${ }^{161}$ In den Anmerkungen zu den Estados generales de tributo der Jahre 1805 und 1810 werden die tributarios medios y enteros weiter ähnlich definiert wie in den Jahrhunderten zuvor, mit einigen regionalen

158 Z.B. Salvador Guerra, vecino de Zinapequaro ante José Antonio Alcozer teniente de cura y juez eclesiastico de este pueblo, presento informacion para comprobar su calidad, estado, vecindad, oficio, edad y generales de la ley para que se le declare libre de los tributos de los sirvientes de su hacienda de Xaripeo que no existen, 10 fs, 1787, AHMM, Hacienda, Caja 5, Exp. 14.

${ }^{159}$ El Intendente de Valladolid, sobre que a los indios laboríos se le señale igual cuota en los tributos que a los radicados en pueblos, fs 146-150, 27.02.1800, AGNM, Real Hacienda; Tributos; Contenedor 21; Vol. 51; Exp. 6.

${ }^{160}$ Fonseca / Urrutia, Historia general, S. 432-33 (párrafo 53).

${ }^{161}$ Claudia Guarisco, La reconstitución del espacio político indígena. Lima y el Valle de México durante la crisis de la monarquía española, Castelló de la Plana Spain: Universitat Jaume I, 2011, Bd. 28, S. 123; Fonseca / Urrutia, Historia general, S. 441 (párrafo 73); "Artículos 124-141 de la Real Ordenanza“, Art. 137: Exêquacion del Tributo y Servicio Real: quotas que para élla se han de fixar á las Castas tributarias: edades y estados en que deben contribuirlas; y á quiénes se ha de exceptuar. Weitere Ausnahmen von der Tributpflicht, wie etwa für die Inhaber von Ämtern in indigenen Gemeinden, bestanden fort: „Instruccion á que se han de arreglar”, Art. 26: De las Reservas por oficio. Guardino, The Time of Liberty, S. 94 weist für Oaxaca darauf hin, dass die Erhebung von Tribut unter ledigen indigenen Männern kaum Auswirkungen hatte, da die meisten von ihnen sehr jung heirateten.

Jahrbuch für Geschichte Lateinamerikas | Anuario de Historia de América Latina 
Ausnahmen, etwa Yucatán, wo es keine medios tributarios gab. ${ }^{162} \mathrm{Im}$ Gegensatz zu Peru wurde nicht versucht, die Befreiung der Mestizen von der Tributpflicht anzutasten. ${ }^{163}$

Die afrikanischstämmige Bevölkerung besaß keinerlei Anrecht auf Ländereien, allerdings konnte sie durchaus Ländereien pachten. ${ }^{164}$ In den Fällen, in denen sie ein Handwerk ausübte, hing auch bei ihnen, vergleichbar mit den Indigenen, die Tributzahlung vom Handwerk ab. ${ }^{165}$ Trotz der bereits im 16. Jahrhundert etablierten allgemeinen Tributpflicht für die afrikanischstämmige Bevölkerung wies Gálvez darauf hin, dass viele von ihnen zur Zeit seiner Visitation keinen Tribut zahlten. ${ }^{166}$ Ähnlich wie bei den laboríos scheint es auch bei der afrikanischstämmigen Bevölkerung im 18. Jahrhundert vermehrt Versuche gegeben zu haben, von der Kategorie der Mulatten hin zu der der Mestizen oder Kreolen zu wechseln um keinen Tribut mehr zu zahlen. ${ }^{167}$ Offiziell befreit waren innerhalb der afrodescendientes nur die

162 „Advertencias, adiciones, cuadros”; “Advertencias sobre los tributos de 1810 de Juan Antonio Vazquez (1818). 'Estado general de los Tributos, impuesto de Comunidad y Medios reales de Ministros y Hospital que segun las últimas Matrículas ó Retasas importaba cada an̂o la contribucion de los Yndios, Negros y Mulatos libres y las demás castas tributarias del Reino de N. E. ... AGN, Indiferente Virreinal, caja 2388, fs. 315: „Real Cédula del $1^{\circ}$. de marzo de 1815 sobre que se restablezca el ramo de Tributos con el nombre de Contribución”, entre fojas 61v y 69. Eine Kopie dieses Dokuments befindet sich Archivo General de Indias de Sevilla, México, 2376: Real Hacienda, Años 18171824, legajo 1. Superior Gobierno. Año 1819”: Martha Terán (Hg.), Tributos tardíos de la Nueva España. Programa interactivo, México, D.F.: 2016, S. 192-197.

163 „Real Provision acordada”, Que el Real Acuerdo, y no â las Justicias toca el declarar la excempcion â los Caziqués, y Mestizos, y formalidades que han de preceder.

${ }^{164}$ Beispiele sind: Padrón de los indios terrasqueros y laboríos que se han encontrado en las haciendas y ranchos de la jurisdicción de Tétela del Río, cuya recaudación es de cuenta del subdelegado y entrega a los oficiales de México, 134 fs, 1800, AGNM, Indiferente Virreinal, Caja 5771, Exp. 60; Joseph de Sisneros mulato libre sobre arrendamiento de tierras, 1713, AHCP, Caja 21A, Exp. 2; ARC D. Juan Antonio. Im letzten Fall arbeitete gar ein Indigener für den Besitzer, der als zambo bezeichnet wird, auf dessen Land.

165 „Real Provision acordada”, Que se Empadrone á los Negros, y Mulatos libres con expression de sus Oficios, y se haga que los exerciten.

${ }^{166}$ Fonseca / Urrutia, Historia general, S. 440 (párrafo 70).

167 Guardino, The Time of Liberty, S. 95 weist für Oaxaca daraufhin, dass viele Schwarze es scheinbar im Verlauf des 18. Jahrhunderts schafften, als Kreolen oder Mestizen anerkannt zu werden, um der Tributpflicht zu entgehen. Diese Vermutung bestätigen verschiedene Petitionen aus Michoacán aus dem 18. Jahrhundert. In diesen versuchten Mulatten als Mestizen oder Spanier anerkannt zu werden - meist erfolgreich; z.B.: Información que ofrecio dar Rafael Belarano para exhonerarse de pagar tributo, 8 fs, 1790, AHCP, Caja 59B, Exp. 1; Simón y Vicente Vivanco, hermanos vecinos del pueblo de Indaparapeo, presentan una certificación, 5 fs, 1727, AHMM, Gobierno, Caja 55, Exp. 25; Petición de Pedro Regalado y Simon Ortiz de Sarate, hermanos, vesinos 
Milizionäre, allerdings nur in den Provinzmilizen und nur für die Dauer ihrer Mitgliedschaft. ${ }^{168}$

Abschließend ist darauf hinzuweisen, dass es vor den Aufständen Tupac Amarus und Tupac Kataris in Peru in den 1780er Jahren in Hispanoamerika keine größeren von Indigenen geführten Bewegungen gegeben hatte, die die Abschaffung des Tributes und damit die Aufkündigung des „kolonialen Paktes“ forderten. Vielmehr wurde von Indigenen teilweise die Sorge geäußert, dass sie bei einer Abschaffung des Tributes anderen Steuern wie etwa der alcabala unterworfen wären. ${ }^{169}$ Inwiefern die Aufstände unter Tupac Amaru und Tupac Katari Ende des 18. Jahrhunderts die Kolonialherrschaft insgesamt beenden wollten, wird nach wie vor kontrovers diskutiert. ${ }^{170}$ In Neuspanien gab es keine vergleichbaren Aufstände. ${ }^{171}$

desta ciudad y dueños del obrage en ella, 4 fs, 1740, AHMM, Gobierno, Caja 55, Exp. 27.

${ }^{168}$ Instancia de Eusebio Tubera, sobre que se le releve de pagar tributo, fs. 101-104, 19.05.1778, AGNM, Tributos, Vol. 14, Exp. 10; „Instruccion á que se han de arreglar”, Art. 27: Que no estan exênto de Tributo los alistados en Milicias Urbanas, y que la exêncion de Cuerpos Provinciales se entiende con las limitaciones que se expresan.; “Artículos 124-141 de”, 139: Exêncion del Tributo concedida á los Pardos libres que sirvan en las Milicia: cómo, y para qué Cuerpos se debe entender. Siehe auch: Ben Vinson, „Los milicianos pardos y la construcción de la raza en el México colonial”: Signos históricos, 2: 4 (2000), S. 87-106.

${ }^{169}$ Martha Terán, „Extinción de los tributos de la Nueva España, 1810-1822. Tomo II”: Martha Terán (Hg.), Tributos tardíos de la Nueva España. Programa interactivo, México, D.F.: 2016, i-v.; Granados, En el espejo, S. 222-223.; Pollack, „Hacia una historia”, S. 89.

${ }^{170}$ Siehe z.B. Scarlett O'Phelan Godoy, „Hacia una tipología y un enfoque alternativo de las revueltas y rebeliones del Perú colonial (Siglo XVIII)”: Jahrbuch für Geschichte von Staat, Wirtschaft und Gesellschaft Lateinamerikas, 21 (1984), S. 127-153; David Cahill, „Becoming Inca. Juan Bustamente Carlos Inca and the Roots of the Great Rebellion”: Colonial Latin American Review, 22: 2 (2013), S. 259-280; Alberto Flores Galindo, Buscando un Inca. Identidad y utopia en los Andes, Lima: Ed. Horizonte, 1994; Luis Miguel Glave, „The 'Republic of Indians' in Revolt. (ca. 1680-1790)”: Frank Salomon / Stuart B. Schwartz (Hg.), South America, Cambridge: Cambridge University Press, 1996, S. 502-557; Stavig, The World of Tupac Amaru.

${ }^{171}$ Verschiedene kleinere Aufstände hatten nicht nur mit Änderungen im Bereich der Tributpflicht zu tun, sondern auch mit anderen Maßnahmen, etwa der Verbannung der Jesuiten im Jahr 1767: Felipe Castro Gutiérrez, „Los Indios y la Justicia del Rey. Una historia de manipulaciones recíprocas”: Andrew Roth-Seneff (Hg.), Caras y máscaras del México étnico. Soberanías y esferas ritualizadas de intercambio, Zamora: El Colegio de Michoacán, 2011, S. 36.

Jahrbuch für Geschichte Lateinamerikas | Anuario de Historia de América Latina 


\section{Der lange Weg zur Abschaffung im 19. Jahrhundert}

Pollack ist der Ansicht, dass es bereits Ende des 18. Jahrhunderts Stimmen gab, die die Abschaffung des Tributs forderten, unter anderem, um die bessere Einbindung der Indigenen in den Markt zu gewährleisten. ${ }^{172}$ Die Abschaffung des Tributs gehörte von Beginn der Kämpfe um die Unabhängigkeit in den Jahren 1810 (Neuspanien) bzw. 1811 (Peru) zu den Forderungen der Aufständischen. ${ }^{173}$

Im Zuge des Unabhängigkeitsprozesses in Hispanoamerika, in dem die Cortes de Cádiz von 1810-1813 eine wichtige Rolle spielten, wurde die Tributpflicht abgeschafft; teilweise allerdings nur, um in neuem Gewand wieder eingeführt zu werden. Insbesondere in Peru war so der Weg zur Abschaffung ein längerer Prozess.

Im Jahr 1810 bzw. 1811 erklärten die Cortes de Cádiz die Tributpflicht für beendet. ${ }^{174}$ Daran hatte sich auch die Vizekönige in Peru und Neuspanien zu halten, die, nicht zuletzt aufgrund massiver Einkommensverluste, bisweilen gar nicht glücklich darüber waren. Teilweise wurde die Abschaffung der Tribute dann auch nicht umgesetzt. ${ }^{175}$ Die Cortes de Cádiz erkannten außerdem alle Indigenen, Spanier und deren Nachkommen als Staatsbürger an, jedoch die Afroamerikaner lediglich als Mitglieder der Nation ohne gleichwertige Rechte. ${ }^{176}$

Nach seiner Rückkehr auf den Thron 1814 ordnete König Ferdinand VII. 1815 die Einführung einer contribución del real tributo an, die den bisherigen Tribut ersetzen sollte. ${ }^{177}$ Diese Anordnung wurde lediglich in

172 Pollack, „Hacia una historia”, S. 128.

${ }^{173}$ Granados, En el espejo, unterstreicht für Neuspanien insbesondere die Rolle der laboríos in den ersten Kämpfen im Bajío, weist jedoch die Interpretation zurück, dass die Abschaffung des Tributes von den Anführern des Kampfes versprochen wurde, um mehr Unterstützer zu gewinnen. Für Peru: Timothy Eagan Anna, La caída del gobierno español en el Perú. El dilema de la independencia, Lima: IEP Inst. de Estudios Peruanos, 2003, Bd. 35, S. 88.

${ }^{174}$ Reyes García (Hg.), Catálogo del Ramo Tributo, S. V gibt das Jahr 1810 an, Claudio Espinoza César, „República, tierra y comunidad de indios. De las Cortes de Cádiz a Bolívar, Piura-Catacaos, siglo XIX”: Investigaciones sociales, 12: 21 (2008), S. 237-268. Gibt für die Abschaffung der Tributpflicht das Jahr 1810 an das Jahr 1811.

${ }^{175}$ Für Neuspanien: Terán, „Geografía de los partidos”, S. 76; für Peru: Espinoza César, „República, tierra y”, S. 247.

${ }^{176}$ Grewe, Ethnizität, Staatsbürgerschaft und Zugehörigkeit, S. 276.

177 „Opiniones sobre el tributo. Manuel Merino, Valladolid, 27 de julio de 1816. “Real Cédula del $1^{\circ}$ de Marzo de 1815 . Sobre que se restablezca el ramo de Tributos con el nombre de Contribución”. AGN, Indiferente Virreinal, caja 2388, exp. 1, fs. 285r-288v”: Martha Terán (Hg.), Tributos tardíos de la Nueva España. Programa interactivo, México, D.F.: 2016, S. 104-106.; Martha Terán, „Restablecimiento de los Tributos de la Nueva 
den von der Krone kontrollierten Gebieten, folglich in weiten Teilen des Vizekönigreiches Peru jedoch in Neuspanien lediglich in Yucatán, umgesetzt. ${ }^{178}$ Mit der Unabhängigkeit wurde die königliche Abgabe sowohl in Peru als auch in Neuspanien im Jahr 1821 offiziell abgeschafft. ${ }^{179}$ Doch kurz darauf wurden in den jungen Nationalstaaten sogenannte contribuciones directas erhoben, mit unterschiedlichen regionalen Ausprägungen.

Da in Neuspanien die Unterscheidung nach calidades aufgehoben wurde, und sowohl Indigene als auch afrodescendientes neben Mestizen und Kreolen als Staatsbürger anerkannt wurden, waren auch alle abgabenpflichtig. ${ }^{180}$ Allerdings gab es verschiedene Kriterien, wie etwa Besitz, Einkünfte und Beruf, die dazu führten, dass die Abgaben vor allem von Indigenen erhoben wurden, was de facto einer Kontinuität mit dem kolonialen Tribut herstellte. ${ }^{181}$ Außerdem gab es weiterhin Gruppen, die von staatsbürgerlichen Rechten ausgenommen waren. Dies traf in Neuspanien auf die vagos bzw. vagabundos zu. ${ }^{182}$

In Peru war die contribución personal bis 1854 eine Kopfsteuer, die explizit nur von der indigenen Bevölkerung eingezogen wurde. Im Gegenzug musste die indigene Bevölkerung jedoch nicht die Abgaben zahlen, die andere Bevölkerungsgruppen entrichten mussten, wie die alcabala und Abgaben auf Ländereien und Handel sowie Produkte.

España. Tomo III”: Martha Terán (Hg.), Tributos tardíos de la Nueva España. Programa interactivo, México, D.F.: 2016, S. I-V; eadem, „Geografía de los partidos”, S. 74-75 weist darauf hin, dass Ferdinand VII. die Wiedereinführung des Tributs in alter Form in Erwägung zog.

${ }^{178}$ Yucatán war von den Aufständen kaum betroffen. Der Intendant von Yucatán befahl 1814, nachdem er von der Rückkehr Ferdinands auf den Thron erfahren hatte, die Eintreibung einer „contribución extraordinaria“. Pollack, „Hacia una historia“, S. 127128.

179 Für Peru weist Cecilia Méndez Gastelumendi, El poder del nombre, o la construcción de identidades étnicas y nacionales en el Perú. Mito e historia de los iquichanos, Lima, Perú: Instituto de Estudios Peruanos, 2002, S. 69 auf ein Dekret von San Martín 1821 hin. Für Neuspanien: Reyes García (Hg.), Catálogo del Ramo Tributo, S. V sowie Terán, „Restablecimiento de los tributos”.

${ }^{180}$ Grewe, Ethnizität, Staatsbürgerschaft und Zugehörigkeit, S. 280-281.

${ }^{181}$ Pollack, „Hacia una historia”, S. 131. Sánchez Silva, Indios, comerciantes y burocracia, S. 112 zeigt auf, dass die Regierung in Oaxaca diese Kontinuität auch selbst argumentativ herstellte. Sie begründete die Pflicht der contribución personal für Indigene damit, dass die Indigenen diese Abgabe ja bereits seit undenklicher Zeit zahlten.

182 Sebastian Dorsch, Verfassungskultur in Michoacán (Mexiko). Ringen um Ordnung und Souveränität im Zeitalter der Atlantischen Revolution, Köln, Weimar, Wien: Böhlau, 2010, S. 396-397; Congreso General, Impreso titulado Proyecto de la Primera Ley Constitucional, pp. 4-8 (impreso) fs 9-14 (manuscrito), 17.10.1835, AGNM, Historia, Vol. 560.

Jahrbuch für Geschichte Lateinamerikas | Anuario de Historia de América Latina 
Daher ist die contribución personal in Peru noch deutlicher als Fortführung des kolonialen Tributs interpretiert worden. ${ }^{183}$ Auch cholos und zambaigos mussten bis 1854 eine spezielle contribución zahlen. ${ }^{184}$ Von 1855 bis 1895 gab es eher regional und territorial ausgerichtete Abgaben. Diese wurden in geringer Höhe von der landbesitzenden Elite entrichtet, und in größerem Ausmaß von der indigenen Bevölkerung. Mestizen und Indigene, die keiner Gemeinde zugeordnet waren, entgingen der Abgabenzahlung laut Contreras zumeist wegen des geringen Umfangs ihres Besitzes oder der mangelnden Kontrolle desselben. ${ }^{185}$

\section{Schlussbetrachtung}

Zusammenfassend lässt sich festhalten, dass sowohl Tribut- als auch Arbeitspflichten in den spanischen Vizekönigreichen Neuspanien und Peru grundsätzlich als Fortführung vorspanischer Praktiken zu sehen sind und dieser Fortbestand ein wichtiges Element zur Legitimierung derselben darstellte. Allerdings gab es unter der spanischen Herrschaft weitreichende Veränderungen, auch was das Ausmaß der Belastung der tributpflichtigen Bevölkerung anging. Im Laufe der Kolonialzeit kam es immer wieder zu Änderungen am Tributsystem, sowohl was die Gesetzgebung, als auch deren Umsetzung angeht. Herauszuheben sind hier sicherlich die bourbonischen Reformen im 18. Jahrhundert, die gleichwohl teilweise nur eine bereits bestehende Rechtsprechung nachhaltiger als zuvor durchsetzten. Die bourbonischen Reformen führten zu einer deutlichen Steigerung der Tributeinnahmen, deren Gesamtsummen für die beiden Vizekönigreiche sich interessanterweise trotz aller Unterschiede im Großen und Ganzen über die Kolonialzeit hinweg ähnlich entwickelten, trotz teils erheblicher Unterschiede in der Tributhöhe. ${ }^{186}$

Die Unterschiede zwischen den beiden Vizekönigreichen und auch die regionalen Unterschiede innerhalb der beiden Großregionen lassen sich zum jetzigen Zeitpunkt nur bedingt erklären. Ein wichtiger Faktor war das jeweilige Wirtschaftssystem. So führte die große Bedeutung der Silberminen im Süden Perus und im Norden Neuspaniens während deren

\footnotetext{
183 Contreras, „El impuesto de la contribución”, S. 68, 102-103.

184 Mansilla Escobedo, „El tributo de los zambaigos”, S. 52-54.

185 Contreras, „El impuesto de la contribución”, S. 104.

186 Klein, The American Finances, S. 21.
} 
jeweiliger Hochphase zu einer stärkeren Bedeutung der Arbeitsdienste bzw. der „freien“ Lohnarbeit im Verhältnis zu den Tributzahlungen. Sowohl Minen, als auch Haciendas sowie Zucker- und Textilmühlen förderten die Migration und führten zur Entstehung entsprechender „migrantischer“ Kategorien, die sich von unterschiedlichen vorspanischen Ausgangspunkten her entwickelten. Weitere Faktoren sind sicherlich in den Personen der höheren Kolonialverwaltung, etwa den Vizekönigen oder Visitadoren $\mathrm{zu}$ suchen. Amtsinhaber wie Vizekönig Toledo und die Visitadoren de la Palata und Areche in Peru, der Vizekönig Mendoza, der in Neuspanien und Peru diente, und der Visitador Gálvez in Neuspanien, prägten die jeweilige regionale Ausprägung kolonialer Politik. Um die Fragen nach den Ursachen der Divergenzen abschließend zu beantworten, bedarf es jedoch weiterer vergleichender Forschung.

Es gab jedoch auch grundlegende Gemeinsamkeiten. In beiden Vizekönigreichen gab es während der gesamten Kolonialzeit drei große Gruppen an tributpflichtiger Bevölkerung: als sesshaft kategorisierte Indigene, als „Migranten“ und landlos kategorisierte Indigene, sowie die afrikanischstämmige Bevölkerung. Mestizen und Spanier waren von der Tributpflicht ausgenommen. Die Hauptunterschiede zwischen den Vizekönigreichen lagen in der Durchsetzung der Tributpflicht für die afrikanischstämmige Bevölkerung, in unterschiedlichen Arbeitspflichten sowie in der divergierenden Kategorisierung von Migrant_innen.

Die Zuordnung zu diesen Kategorien hing zum einen mit Landbesitz, zum anderen mit der zugeschriebenen calidad zusammen, die wiederum durch Kriterien wie Abstammung und Reputation bestimmt wurde. Die Kategorien waren statisch und erblich konzipiert. Allerdings war es in der Praxis durchaus möglich, die Kategorie im Laufe des Lebens zu wechseln.

Die Obliegenheiten der tributpflichtigen Bevölkerung änderten sich im Laufe der Kolonialzeit ebenso wie das Verhältnis der Kategorien untereinander. Viele grundsätzliche Aspekte des Tributsystems gingen im 16. Jahrhundert vom neuspanischen Modell aus, das teilweise auf Peru übertragen wurde.

Trotz der Intention der Krone, die Belastungen für die indigene Bevölkerung zu beschränken, waren Tribut- und Arbeitspflicht ein wichtiger Grund für die Migration großer Teile der indigenen Bevölkerung. Durch die Kategorisierung als „Migranten“ waren sie zumeist von den Arbeitspflichten befreit und mussten einen geringeren Tribut zahlen, der teilweise für sie von ihren spanischen Arbeitgebern 
entrichtet wurde. Aufgrund einer unterschiedlich starken Kategorisierung von „Migrant_innen“ in vorspanischer Zeit bildeten sich in Neuspanien und Peru unterschiedliche „migrantische“ Kategorien heraus. In Peru fügten sich die indios forasteros in die lokale soziale Struktur ein, die noch sehr lange durch den Fortbestand vorspanischer korporativer Abstammungseinheiten wie dem ayllu geprägt war. Dadurch, dass die Zuordnung zu „migrantischen“ Kategorien erblich war, migrierten nicht alle derart kategorisierten Personen selbst, sondern stammten teilweise nur von Migranten ab. Sowohl die Kategorie der yanaconas de españoles als auch der laboríos war gleichzeitig eine Arbeitskategorie, da viele der so Kategorisierten für Spanier auf Haciendas, in Zuckermühlen und Minen arbeiteten. Allerdings gab es bei den yanaconas del rey starke Überlappungen mit der Kategorie des indio forastero. Bei den neuspanischen laboríos gab es unterschiedliche Grade der Intensität der Beziehungen zu den indigenen Gemeinden. Ein Teil der laboríos praktizierte eine temporäre und zirkuläre Migration, während andere die Beziehungen zu indigenen Gemeinden dauerhaft abbrachen und zusammen mit ihren Nachkommen die Haciendas als dauerhaften Wohnsitz wählten. Auch der Grad der Abhängigkeit variierte. Es gab sowohl selbstständige laboríos als auch jene, die als unfreie Schuldknechte arbeiteten. Insgesamt scheint die Durchsetzung der Tributpflicht in den „migrantischen“ Kategorien sehr viel schwächer gewesen zu sein als bei den als sesshaft kategorisierten Indigenen.

Abgesehen von den unterschiedlichen „migrantischen“ Kategorien war ein weiterer wichtiger Unterschied zwischen Neuspanien und Peru, dass in Neuspanien die Tributpflicht für die afrikanischstämmige Bevölkerung sehr viel umfassender durchgesetzt wurde als in Peru, wo bis zum Ende der Kolonialzeit breite Teile der afrikanischstämmigen Bevölkerung den Zahlungen entgehen konnten, auch wenn sie nicht als Milizionäre dienten. Eine erste, vorsichtige Hypothese besagt, dass die größeren Freiheiten der afrikanischstämmigen Bevölkerung in Peru möglicherweise in der militärischen Bedeutung entsprechender Milizen begründet lagen.

Frauen tauchten in der Tributgesetzgebung und in Auseinandersetzungen um deren Anwendungen in der Regel nur am Rande auf, da sie zwar zusammen mit ihren Ehemännern für die Erwirtschaftung des Tributs tätig waren, jedoch zumeist lediglich die Männer als Tributzahler angesehen wurden. Allerdings gibt es einige Hinweise darauf, dass ledige und verwitwete Frauen, insbesondere 
Mulattinnen, zeitweise auch Tribut zahlen mussten. Diese Praxis wurde schließlich im Rahmen der bourbonischen Reformen abgeschafft.

Ziel der bourbonischen Reformen war vor allem die stringentere Durchsetzung der Tributpflicht, gerade in den migrantischen und afrikanischstämmigen Bevölkerungsgruppen, zur Steigerung der Einnahmen. In Peru sollte dies durch eine Angleichung der Kategorie der forasteros und yanaconas an die des originario stattfinden, die jedoch nur partiell gelang und vielmehr zu einer Aufsplittung in forasteros con und forasteros sin tierras führte. Unter der afrikanischstämmigen Bevölkerung wurden nun vor allem die cholos und zambos/zambaigos verstärkt zur Zahlung verpflichtet. In Neuspanien war ein wichtiges Ziel die Abschaffung der medios tributarios und somit eine Erweiterung der Gruppe, die vollen Tribut zahlte. Dies scheiterte jedoch. Weitaus erfolgreicher war hingegen die Umsetzung einer separaten Registrierung der drei Kategorien indios de pueblo, indios laboríos und der negros y mulatos die wohl auch zu einer Steigerung der Einnahmen bei den beiden letztgenannten Gruppen führten; wobei gleichwohl die Eintreibung der tributos de vagos weiterhin die koloniale Administration vor große Herausforderungen stellte. 